\title{
PERÍCIA CONTÁBIL-FINANCEIRA E OS SISTEMAS DE AMORTIZAÇÃO: SISTEMA FRANCÊS VERSUS SISTEMA DE EQUIVALÊNCIA A JUROS SIMPLES
}

\author{
ACCOUNTING-FINANCIAL EXPERTISE AND AMORTIZATION SYSTEMS: FRENCH SYSTEM \\ VERSUS SIMPLE INTEREST EQUIVALENCE SYSTEM
}

\author{
ANDRÉ SEKUNDA \\ Centro Universitário Dinâmica das Cataratas - UDC \\ Mestre em Contabilidade \\ Orcid: http://orcid.org/0000-0001-9684-8353 \\ E-mail: andresekunda@gmail.com \\ Endereço: Rua Campos do Jordão, 106, Jardim Ipê. Foz do Iguaçu/PR.
}

\begin{abstract}
RESUMO
Este artigo analisa as diferenças entre os fluxos de caixa existentes em um contrato de financiamento de veículos, amortizado pelo sistema francês de amortização (Tabela Price) e o sistema de equivalência a juros simples (SEJS), mensurando os efeitos dessa diferença no patrimônio pessoal do mutuário. A pesquisa, de natureza qualitativa e quantitativa (qualiquanti), é conduzida sob forma de estudo de caso, analisando um processo real (ação revisional de contrato) movido por J.S.F. contra a XX Financeira S/A. São realizados os cálculos relativos aos dois sistemas de amortização em discussão, analisando cada um deles e apontando os valores devidos ao mutuário em decorrência dos pagamentos efetuados a maior. Como principais achados, verificou-se que a taxa de juros informada em contrato pela Financeira, não correspondia à taxa efetivamente praticada para cálculo da prestação, o que pode ser oriundo de mero erro de procedimento, por parte da financeira ou de má-fé. Além disso, identificou-se que a economia mensal para o mutuário, caso o contrato tivesse sido amortizado desde o início pelo SEJS, seria de $\mathrm{R} \$ 168,73$, e que o valor total a ser restituído pela Financeira ao autor da ação, devidamente corrigido e com juros, é de $\mathrm{R} \$ 16.051,52$. Conforme mencionado ao longo do trabalho, embora ações judiciais sejam recorrentes no Brasil, a discussão envolvendo sistemas de amortização e taxas de juros praticadas, está longe de uma solução final, o que pode gerar certa insegurança jurídica, tanto para as instituições financeiras quanto para os mutuários.
\end{abstract}

Palavras chave: Perícia contábil. Sistema francês de amortização. Sistema de equivalência a juros simples .

\begin{abstract}
This article analyzes the differences between the cash flows existing in a vehicle finance agreement, amortized by the French amortization system (Table Price) and the simple interest rate system (SEJS), measuring the effects of this difference on the personal borrower. The qualitative and quantitative research (quali-quanti) is conducted in the form of a case study, analyzing a real process (revision of contract) moved by J.S.F. against XX Financeira S/A. The calculations of the two amortization systems under discussion are carried out, analyzing each one of them and indicating the amounts due to the borrower as a result of the payments made to the larger one. As the main findings, it was verified that the interest rate reported in contract by Financeira did not correspond to the rate actually used to calculate the
\end{abstract}

Data de submissão: 04/02/2019. Data de aceite: 04/08/2019. Data de publicação: 13/08/2019. 
installment, which may be due to a mere procedural error on the part of the financial institution or in bad faith. In addition, it was identified that the monthly savings to the borrower, if the contract had been amortized from the beginning by the SIS, would be R\$ 168.73 , and that the total amount to be refunded by the Financial to the author of the action, duly adjusted and with interest, is $\mathrm{R} \$ 16,051.52$. As mentioned throughout the paper, although lawsuits are recurrent in Brazil, the discussion involving amortization and interest rates practiced is far from a final solution, which may generate some legal uncertainty, both for financial institutions and for borrowers.

Keywords: Forensic accounting. French depreciation system. System of simple interest equivalence.

\section{INTRODUÇÃO}

A contabilidade constitui um sistema de informação destinado a melhorar o processo de tomada de decisão (FIGUEIREDO; MOURA, 2001). O emprego da informação contábil se dá nos mais diferentes contextos. É muito comum o emprego da informação da contabilidade para tomada de decisões no âmbito das empresas, porém, há tempos que em outros contextos, que não apenas nas organizações a informação contábil subsidia o processo decisório.

Neste sentido, um ambiente em que a informação contábil ganha relevante destaque e apoia decisões é no âmbito do Poder Judiciário. Em muitas espécies de processos, a informação contábil, consubstanciada no laudo pericial, é fator determinante para a decisão processual.

Quando o magistrado confia no trabalho e na informação contábil do perito, somandose a isso a isenção do profissional, a prova pericial contábil acaba por tornar-se a mais importante dentro de um processo, de modo que, não raro, o juiz termina por decidir as lides em função e de acordo com as conclusões expostas no laudo pericial (NEVES JUNIOR; CERQUEIRA; GOTTARDO, 2013).

Ou seja, a informação contábil há tempos ultrapassou as fronteiras das empresas e apoia o processo decisório em outras instâncias, como a judicial. No âmbito do processo judicial, a informação contábil se manifesta por meio de um laudo pericial, elaborado no bojo de uma perícia.

A perícia constitui uma espécie de prova no direito brasileiro, e é demandada nas ações judiciais quando o juiz depende de conhecimentos técnicos ou científicos para o julgamento da causa, nos termos do art. 156 do Código de Processo Civil - CPC (BRASIL, 2015).

A perícia contábil é uma das espécies de perícias mais comuns em processos judiciais de diferentes naturezas, visto que trata do patrimônio das pessoas físicas e jurídicas. Portanto, é muito comum que em ações judiciais, arbitrais, e até mesmo em conflitos extrajudiciais, seja demandada uma perícia de natureza contábil (NEVES JUNIOR; BRITO, 2007).

Dada a amplitude do campo de atuação da contabilidade, a perícia contábil pode incidir sobre diferentes relações jurídicas, como em processos trabalhistas para realização da liquidação de sentenças em favor dos empregados, ações de natureza previdenciária, com objetivo de apurar o valor dos benefícios previdenciários devidos ao segurado, ações de natureza cível para atualização de valores e recálculos de financiamentos à taxas de juros de mercado, demandas societárias, como para a apuração de haveres de sócio, dentre tantas outras situações que envolvam o patrimônio de pessoas físicas ou jurídicas (ZANNA, 2013).

Dentre todas as possibilidades de aplicação da perícia contábil, uma possui grande destaque: a perícia contábil envolvendo planos e sistemas de amortização, em especial em 
contratos amortizados pelo sistema francês de amortização (popularmente conhecido, no Brasil, como "Tabela Price").

Existem muitas razões que levam os litigantes a ajuizar demandas como essas no Brasil, como a falta de segurança jurídica do sistema de contratos brasileiro, as falhas nas redações dos contratos celebrados entre as partes, que empregam redações dúbias e com diversas interpretações, a própria natureza belicosa do brasileiro em questões processuais, mas certamente o motivo mais usado para fundamentar tais ações é a alegada proibição da incidência de juros sobre juros no Brasil, prevista no Decreto no 22.626, de 7 de abril de 1933, também conhecido como a "Lei da Usura".

Independentemente das razões que motivam tais ações, fato é que, de maneira muito recorrente, são ajuizadas demandas judiciais visando discutir contratos que são amortizados com base no sistema francês de amortização, e os pedidos nas ações são igualmente diversos.

Existem ações visando afastar o sistema de amortização francês, substituindo-o por algum outro à juros simples (como o sistema de amortização de Gauss, ou método de amortização a juros simples - MAJS), visando o recálculo do financiamento à taxas médias de mercado, visando afastar do capital financiado valores não contratados, como taxas de abertura de crédito, enfim, a gama de demandas judiciais envolvendo a questão é gigantesca e a atuação em processos dessas naturezas, faz parte do dia-a-dia profissional do perito contador.

E os Tribunais, por sua vez, exaram as mais diferentes sentenças possíveis a respeito do tema, não havendo absolutamente nenhuma uniformidade no tratamento jurídico da questão.

Por conta disso, e tendo em vista todos os problemas empíricos que contratos amortizados com base no sistema francês de amortização causam tanto aos litigantes, quanto aos juízes, quanto, inclusive, aos peritos contadores, o presente estudo visa responder à seguinte questão de pesquisa: Qual a economia proporcionada ao mutuário pela amortização de um contrato de financiamento pelo SEJS em detrimento da tabela Price?

Com isso, o objetivo do trabalho é analisar a economia proporcionada ao mutuário que tem seu contrato de financiamento de veículo amortizado pelo sistema de equivalência a juros simples em detrimento da amortização pelo sistema francês de amortização (tabela Price), mensurando a diferença dos fluxos de caixa gerada pela substituição do sistema de amortização e seus efeitos no patrimônio pessoal do mutuário.

Para responder ao problema, far-se-á a análise de um contrato real de financiamento de veículos, sub judice, originalmente amortizado pelo sistema francês de amortização, oferecendo o recálculo do contrato à juros simples, com base nas disposições previstas na sentença.

Embora o tema seja recorrente no dia-a-dia profissional, pouquíssimos estudos aplicados, como propõe a presente pesquisa, são realizados. Diversos estudos na área de perícia contábil são encontrados abordando questões, como a percepção de juízes sobre a qualidade do laudo pericial, a percepção dos peritos sobre o mercado de trabalho, a importância da perícia contábil para o Poder Judiciário, e outros, porém, estudos sobre perícia contábil, com aplicações práticas e empíricas como ora se propõe, são escassos.

Nesse sentido, Sandrini (2007), em seu trabalho dissertativo sobre sistemas de amortização e capitalização de juros, pontuou que um dos incentivos à realização do trabalho, era o fato de que o tema era pouco contemplado por revistas científicas nacionais e estrangeiras, o que tornou-se um motivo a mais para a realização da pesquisa.

Com isso, acredita-se que o trabalho oferece sua parcela de contribuição tanto à academia, propondo uma pesquisa sobre tema pouco explorado em periódicos e eventos da 
área contábil, quanto aos profissionais, pois discute questões umbilicalmente ligadas ao seu dia a dia profissional, sendo que pode servir de fonte de pesquisas futuras e material, para fundamentação da sua atividade prática.

Além disso, acredita-se que o estudo contribui com a literatura acerca da perícia, em especial da perícia ligada a contratos financeiros, ao realizar uma revisão robusta dos sistemas de amortização contratual sob análise (Price e SEJS), discorrendo sobre seu funcionamento, demonstrando como se dá sua aplicação, o funcionamento de suas equações e analisando sua aplicação em um caso concreto. Com isso, outros estudos podem se utilizar dos temas discutidos aqui para motivar futuras pesquisas.

Esses motivos justificam a realização da presente pesquisa, visto que pode contribuir tanto com os profissionais que labutam na área, quanto com a academia, oferecendo uma pesquisa com abordagem pouco explorada no meio acadêmico.

Por fim, o estudo possui a seguinte estruturação: esta seção introdutória, uma seção de revisão de literatura, uma seção expondo os procedimentos metodológicos, uma seção de análise dos resultados e, por fim, as considerações finais.

\section{REVISÃO DE LITERATURA}

\subsection{ASPECTOS CONCEITUAIS, PROCESSUAIS E PROFISSIONAIS DA PERÍCIA CONTÁBIL}

A perícia contábil, em seu conceito clássico, refere-se a um trabalho de notória especialização, feito com o objetivo de obter prova ou opinião que se destina a orientar uma autoridade formal no julgamento de um fato (MAGALHÃES, 2017).

No caso da perícia contábil, as normas elementares que balizam a atuação dos profissionais envolvidos na perícia são o Código de Processo Civil (CPC), aprovado pela Lei 13.105/2015, e as Normas Brasileiras de Contabilidade (NBC), expedidas pelo Conselho Federal de Contabilidade (CFC), relativas à perícia contábil. Atualmente, as duas NBCs mais relevantes sobre a perícia são a NBC TP 01, que estabelece regras e procedimentos técnicos a serem observados pelo perito, e a NBC PP 01, que estabelece procedimentos inerentes à atuação do contador na condição de perito.

Nos termos do art. 156 do CPC, o juiz será assistido por perito quando a prova do fato depender de conhecimento técnico ou científico (BRASIL, 2015). Ou seja, sempre que o juiz se deparar com alguma situação envolvendo questões técnicas no processo, e que isso de alguma forma dificulte seu trabalho de julgar a lide, será nomeado um perito para a realização dos esclarecimentos de todos os aspectos técnicos ao juízo, de forma que o processo possa seguir seu fluxo e ser julgado, dando fim à controvérsia judicial.

Na maioria dos processos em que se demanda a perícia (seja a contábil, seja a de qualquer outra natureza), tem-se a atuação de duas figuras distintas: o perito do juízo e o assistente técnico. No caso da perícia contábil, essas figuras são tratadas por perito-contador (que pode ser nomeado, contratado ou escolhido) e por perito-contador assistente.

De acordo com a NBC PP 01 (CFC, 2015), o perito-contador nomeado é o designado pelo juiz em perícia contábil judicial. Já o contratado é o que atua em perícia contábil extrajudicial. E por fim, o escolhido é o que exerce sua função em perícia contábil arbitral. Por sua vez, o perito-contador assistente é o contratado e indicado pela parte em perícias contábeis, em processos judiciais e extrajudiciais, inclusive arbitral.

Para atuação com a perícia contábil, seja na função de perito-contador ou de peritocontador assistente, os requisitos são, essencialmente, o registro ativo do profissional em Conselho Regional de Contabilidade na categoria de contador (arts. 25, "c" e 26 do Dec. Lei 
9.295/1946 - BRASIL, 1946) e os conhecimentos técnicos acerca da matéria objeto da perícia (BRASIL, 2015).

Saliente-se que nos termos da NBC PP 01 (CFC, 2015), o perito-assistente deve declarar-se suspeito quando, após contratado, verificar a ocorrência de situações que venham suscitar suspeição em função da sua imparcialidade ou independência e, dessa maneira, comprometer o resultado do seu trabalho.

Embora não constitua uma exigência para atuação do perito, o CFC editou a resolução 1.502/16 e alterações, instituindo o Cadastro Nacional de Peritos Contadores (CNPC). O objetivo do cadastro, segundo o próprio CFC, é oferecer ao judiciário e à sociedade uma lista de profissionais qualificados e aptos a atuarem com perícias contábeis.

Atualmente, para compor o CNPC, os profissionais interessados devem ser aprovados em Exame de Qualificação Técnica (EQT), bem como cumprir as demais exigências realizadas pelo Conselho Federal de Contabilidade.

O CPC, em seu art. 465, dispõe que o juiz nomeará perito especializado no objeto da perícia, evidenciando a necessidade de conhecimentos técnicos do perito para atuação, visto que sem tais conhecimentos, não faria sequer sentido a atuação do profissional em meio a questões técnicas especializadas (BRASIL, 2015).

Importante distinção entre o perito-contador e o perito-contador assistente reside no fato de que, nos termos do art. $466 \S 10$ do CPC, os assistentes técnicos não estão sujeitos às causas de impedimento e suspeição, não possuindo, portanto, o dever da imparcialidade, enquanto que, ao perito, cabe o dever de obediência à imparcialidade da sua atuação.

Essa norma possui um efeito prático importante nas atuações de ambos os profissionais, pois enquanto o perito deverá balizar sua atuação pela neutralidade e imparcialidade da apreciação, o assistente técnico pode atuar em defesa do seu contratante, o que, via de regra, coloca peritos e assistentes técnicos em rota de colisão.

Isso porque uma das principais tarefas do assistente técnico, senão a principal, é justamente contrapor os pontos prejudiciais ao seu cliente do laudo pericial emitido pelo perito, em defesa dos interesses da parte que lhe contratou. Evidentemente que se o laudo apresentar pontos favoráveis, o assistente técnico não precisará discordar do ponto de vista do perito em relação a esses pontos.

No tocante ao laudo pericial contábil, este deve seguir a estrutura indicada na NBC TP 01 (CFC, 2015), bem como as disposições constantes do art. 473 do CPC, em especial no tocante a conter a exposição do objeto da perícia, a análise técnica ou científica realizada pelo perito, a indicação do método utilizado, esclarecendo-o e demonstrando ser predominantemente aceito pelos especialistas da área do conhecimento da qual se originou e, por fim, a resposta conclusiva a todos os quesitos apresentados pelo juiz, pelas partes e pelo órgão do Ministério Público (BRASIL, 2015).

E engana-se quem pensa que o trabalho do perito se encerra com a apresentação do laudo pericial, visto que podem ser demandados do perito esclarecimentos e quesitos complementares ao laudo, nos termos do art. 477 do CPC (BRASIL, 2015).

Portanto, pelo exposto, verifica-se que a atuação profissional do perito e do assistente técnico envolve a obediência a uma gama de normas, de procedimentos especiais e de ritos previstos tanto pela legislação processual quanto pelas normas de classe. Apresentados os principais elementos essenciais à atuação do perito, em seguida serão discutidos aspectos específicos da perícia contábil em matéria financeira, em especial em contratos financeiros, que são aqueles que justamente possuem as maiores discussões, sobre questões ligadas à sistemas de amortização. 


\subsection{PERÍCIA CONTÁBIL EM CONTRATOS FINANCEIROS}

Um contrato de financiamento se caracteriza, segundo Zanna (2015), pelo ato de uma das partes da relação contratual adiantar determinada quantia em dinheiro, para que alguém adquira um bem ou um direito, de modo que o tomador do empréstimo devolva esse capital ao agente financeiro em certo número de prestações, sujeitas a uma determinada taxa de juros pactuada entre as partes.

No tocante à pactuação da taxa de juros entre as partes, a Emenda Constitucional $\mathrm{n}^{\circ}$ 40 revogou o então § 3ㅇ do art. 192 da Constituição Federal de 1988 que limitava as taxas de juros reais a doze por cento ao ano. E mais, a Constituição ia além em sua redação original, indicando que a cobrança acima do limite de $12 \%$ seria conceituada como crime de usura, punido, em todas as suas modalidades, nos termos que a lei determinar.

Portanto, segundo Bonfá (2012), após o advento da EC 40, não há mais que se falar em limitação de taxas de juros nas operações praticadas pelas instituições financeiras, sendo esse ajuste de livre iniciativa entre as partes.

Não obstante a isso, uma das demandas judiciais mais comuns na seara contratual, e que mais demandam a atuação do perito contador, refere-se às ações revisionais em que se requer o recálculo de um determinado financiamento, à taxa média de juros do mercado, evidenciando que, embora a legislação tenha evoluído no sentido de não predeterminar limites, à livre contratação da taxa de juros entre agente financeiro e mutuário, a pretensão de muitos litigantes ainda encontra guarida no Judiciário em relação a esse tipo de discussão.

Nesse sentido, um dos argumentos trazidos à discussão em demandas desta natureza, diz respeito aos dispositivos da Lei da Usura e à ocorrência do anatocismo nos contratos de financiamento e empréstimo, em especial naqueles amortizados pelo sistema francês (Tabela Price).

Por anatocismo, segundo Domingues (2011), entende-se a cobrança de juros capitalizados, ou seja, a contagem de juros sobre juros. Em ações envolvendo contratos de financiamentos, o elemento legislativo mais invocado é o Decreto 22.626/1933, que em seu art. 4ำ prevê que é proibido contar juros dos juros: esta proibição não compreende a acumulação de juros vencidos aos saldos líquidos em conta corrente de ano a ano (BRASIL, 1933).

Apimentando ainda mais essa questão, em conjunto com a Lei da Usura, as ações revisionais de forma recorrente citam o enunciado da Súmula 121 do Supremo Tribunal Federal (STF, 1963), que prevê que é vedada a capitalização de juros, ainda que expressamente convencionada. Ocorre que o próprio STF, anos depois, emitiu a Súmula 596, que dispõe que as disposições do Decreto 22.626/1933 não se aplicam às taxas de juros e aos outros encargos cobrados nas operações realizadas por instituições públicas ou privadas, que integram o Sistema Financeiro Nacional (STF, 1976).

Não obstante a mudança de posição do STF, a vedação legal da capitalização anteriormente mencionada foi afastada no âmbito das instituições que compõem o sistema financeiro nacional pela Medida Provisória (MP) 2.170-36/2001, que passou a admitir a capitalização de juros em periodicidade inferior a um ano nos contratos. Segundo o art. 50 da referida MP, nas operações realizadas pelas instituições integrantes do Sistema Financeiro Nacional, é admissível a capitalização de juros com periodicidade inferior a um ano (BRASIL, 2001).

Nesse sentido, Domingues (2011) esclarece que nas operações de crédito realizadas a partir de 31 de março de 2000 por instituição integrante do sistema financeiro nacional, é válida a capitalização dos juros em periodicidade inferior a um ano, desde que expressamente pactuada no contrato. 
Desta forma, desde que os contratos de financiamento celebrados contenham redações claras e bem redigidas no tocante à capitalização dos juros, às taxas praticadas e demais questões legais, não haveria razão para a ocorrência de tantas ações discutindo a temática, porém, não é isso que as estatísticas processuais e o dia-a-dia profissional de peritos contadores revelam.

E na esteira dessa discussão insere-se aquela relativa ao sistema francês de amortização, ou Tabela Price, como é popularmente conhecido no Brasil.

A amortização é típica de contratos de financiamento e empréstimo. Segundo Veras (2001), a amortização refere-se à forma como ocorrerá o pagamento de determinada dívida. Portanto, todo contrato de empréstimo ou financiamento envolve um plano para quitação da dívida, ou seja, sua amortização.

Evidentemente que em uma operação de crédito, além do principal emprestado, o tomador deverá remunerar o capital do agente financeiro, ou seja, deverá pagar juros sobre o valor emprestado, e o sistema de amortização deverá levar em conta também essa circunstância.

Segundo Assaf Neto (2001), os sistemas de amortização mais comuns são o Sistema de Amortização Constante - SAC, Sistema de Amortização Francês (Price) - SAF, Sistema de Amortização Misto - SAM e o Sistema de Amortização Americano - SAA. No entanto, a literatura apresenta muitos outros, como o Sistema de Amortização Alemão, o Sistema de Amortização de Gauss, e tantos outros. Para a discussão, interessa o Sistema Francês de Amortização.

Para Assaf Neto (2001), o que caracteriza o Sistema de Amortização Francês é o fato de que as prestações devam ser iguais, periódicas e sucessivas. Por essa razão, segundo DeLosso, Giovannetti e Rangel (2013), se trata do sistema mais usado no mundo para determinar a amortização e os juros de cada parcela.

El denominado Sistema francés de amortización es el más utilizado. Consiste en amortizar el préstamo de forma progresiva, disminuyendo la cuota de interés al ir amortizando el capital pendiente (IGUAL, 2008). Em tradução livre tem-se que o denominado sistema francês de amortização é o mais utilizado. Consiste em amortizar o empréstimo progressivamente, diminuindo o valor dos juros ao amortizar o saldo devedor do capital.

An important property of such amortization, also called French amortization, that justifies the name of progressive amortization, consists of the fact that the principal repayments increase in geometric progression (GP) with ratio (1+i) (JANSSEN; MANCA; VOLPE, 2013). Em tradução livre tem-se que uma propriedade importante do sistema de amortização francês, que justifica o nome de amortização progressiva, consiste no fato de que as amortizações do principal aumentam em progressão geométrica (GP) com relação (1 + i).

A discussão acerca da capitalização composta no sistema de amortização francês já se inicia na fórmula do cálculo da prestação. Nesse sentido, Zanna (2015) esclarece que no sistema de amortização francês (ou sistema da Tabela Price), a equação contém o coeficiente exponencial, que torna a taxa de juros da operação capitalizada, de forma que as prestações a partir dali calculadas contém um componente de juros e outro de amortização, configurando, assim, o sistema como de capitalização composta.

Ou seja, a discussão sobre a capitalização composta já se inicia no cálculo do valor da prestação a ser paga, que, como dito, no sistema francês é constante. Segundo vasta literatura, a caracterização da composição nesse sistema de amortização se dá pela aplicação do coeficiente exponencial na equação da prestação, o que configura a capitalização composta do referido sistema. 
De igual forma, Sandrini (2007) esclarece que a capitalização composta no sistema francês de amortização está caracterizada por meio do surgimento do elemento $i^{n}$ da equação, resultando na incidência de juros sobre os juros existentes no saldo devedor anterior, devidos (vencidos) e não pagos.

Não obstante a esse entendimento, existem autores que defendem que não ocorre capitalização composta dos juros no sistema de amortização francês. Não aprofundou-se essa discussão teórica visto que não é objeto do artigo adentrar a essa discussão, mas sim caminhar para sua aplicação prática em um julgado real.

Por fim, insta salientar que, conforme Faro (2013), o sistema de amortização francês insofismavelmente se conforma com os fundamentos do regime de juros compostos, porém, desde que não haja prestações em atraso no referido sistema de amortização, não há a presença de anatocismo. Ou seja, aqui o autor traz à discussão a diferença entre anatocismo e capitalização composta, ignorada por parte da literatura. Na opinião de Faro (2013), a capitalização composta não necessariamente configura anatocismo, que se caracteriza pela incidência de juros sobre juros vencidos. Zanna (2015) compartilha de opinião similar à de Faro (2013) nessa distinção entre capitalização composta e anatocismo, fato que, muitas vezes, passa desapercebido pela literatura que trata do tema.

Não por outra razão é a conclusão de Faro (2013) de que conquanto anatocismo implica em juros compostos, o regime de juros compostos não necessariamente acarreta anatocismo.

Toda essa discussão acerca da ocorrência de juros compostos no sistema de amortização francês, fez com que diversos sistemas de amortização alternativos fossem surgindo, na tentativa de afastar a capitalização composta do referido sistema de amortização. Dentre eles pode-se citar o Sistema de Amortização de Gauss e o Sistema de Amortização Constante a Juros Simples, porém, o que será discutido neste trabalho é o Sistema de Equivalência a Juros Simples (SEJS), que pode conter outras denominações, mas que obedecido o rigor técnico na sua elaboração, independentemente da nomenclatura serve aos fins a que se destina.

Assim como no sistema de amortização francês, o sistema de equivalência a juros simples também possui prestações constantes. Seguindo esta metodologia, adota-se como data focal para as análises a data zero, ou seja, a data em que o empréstimo ou o financiamento foi contraído. Ainda segundo Sandrini (2007), segundo este conceito de equivalência a juros simples, o capital obtido em forma de empréstimo ou financiamento é considerado, para fins de cálculo das prestações, como se fossem $n$ capitais distintos, em que $\mathrm{n}$ equivale ao número de prestações previstas para amortização da dívida, cada um no seu respectivo vencimento.

Esse formato para amortização, mesmo com as críticas que recebe de parte da literatura, bem como de profissionais da perícia contábil, vêm atendendo à contento a demanda do judiciário e dos profissionais para oferecimento de uma alternativa coerente de cálculo para o sistema francês de amortização nos casos sub judice em que se discute o sistema de amortização contratual.

Saliente-se que em todo sistema de amortização, a prestação é composta por duas parcelas: a amortização e os juros que remuneram o capital do agente financeiro. Cada uma dessas parcelas (amortização e juros) possui critérios objetivos para cálculo, seja no sistema francês de amortização, seja no sistema de equivalência a juros simples (SEJS), e eles serão mais bem detalhados adiante.

As decisões em relação a modificações no sistema de amortização, afastamento da amortização pelo sistema francês, recálculo de juros à taxa de mercado, e tantas outras 
situações, são comuns no Judiciário Brasileiro, o que exige do perito habilidade e conhecimentos técnicos para oferecer uma opinião técnica adequada face a tantas perspectivas que o tema assume. A seguir, apenas para fins exemplificativos, serão apresentados alguns trechos de acórdãos de processos envolvendo as questões discutidas neste artigo, com objetivo de ilustrar o tamanho do desafio que é a atuação como perito ou assistente técnico nesta seara:

Agravo de Instrumento $\mathrm{n}$ - 2167146-08.2018.8.26.0000. Comarca: São Paulo. 3ạ Vara Cível do Foro Regional do Jabaquara. Agravante: Itaú Unibanco S/A. Agravados: P. C. N. e Outros. CUMPRIMENTO DE SENTENÇA. O método a ser empregado no recálculo de débito determinado por v. Acórdão exequendo, que determina o afastamento da capitalização de juros ou do uso Tabela Price, é o Método e Gauss, que adota juros simples, e não o método SAC, visto que emprega juros compostos como a Tabela Price. ... (c) é incabível o emprego no recálculo do débito do método SAC, conforme arguido pelo banco agravante, visto que deve ser empregado o método de Gauss, nos termos do laudo elaborado pelo assistente técnico dos agravados, pois: (c.1) pela r. sentença e pelo v. Acórdão exequendos, houve determinação para afastar a capitalização de juros; (c.2) o método de Gauss adota juros simples e (c.3) o método SAC emprega juros compostos como Tabela Price. Manutenção das rr. Decisões agravadas. Recurso desprovido (TJSP, 2018).

Neste primeiro julgado, que data de dezembro de 2018, observa-se que o TJSP determinou, na ação, o afastamento da amortização pelo sistema francês e o recálculo por outro sistema de amortização, o Sistema de Gauss. Destaque-se que nem sempre os julgados são tão precisos, indicando ao perito qual deve ser o método alternativo para recálculo do contrato. A seguir será apresentado outro julgado.

APELAÇÃO CÍVEL. AÇÃO REVISIONAL. SISTEMA FINANCEIRO DA HABITAÇÃO. SENTENÇA PROCEDENTE. PRELIMINAR. DECISÃO EXTRA PETITA. AMORTIZAÇÃO. AUSÊNCIA DE PEDIDO. ACOLHIMENTO. PORÇÃO DECOTADA. CAPITALIZAÇÃO DE JUROS. CONSTATAÇÃO PELO USO DA TABELA PRICE E DE TAXAS DE JUROS NOMINAL E EFETIVA DIVERSAS. AFASTAMENTO MANTIDO. SUBSTITUICCÃO PELO CÁLCULO DE JUROS SIMPLES. SUCUMBÊNCIA. MANUTENÇÃO. RECURSO PARCIALMENTE PROVIDO. 2. Ainda que a perícia se manifeste em sentido contrário, tendo em vista que o juiz não está adstrito ao laudo pericial, prevalece o entendimento de que o uso da Tabela Price e a contratação de taxas de juros nominal e efetiva em percentuais diversos implicam em capitalização de juros, a qual deve ser afastada e substituída pelo cálculo de juros simples. TJ-PR - AC: 6789997 PR 0678999-7, Relator: Edson Vidal Pinto, Data de Julgamento: 29/09/2010, 14a Câmara Cível, Data de Publicação: DJ: 501 (TJPR, 2010).

Neste julgado percebe-se que, igualmente, o Tribunal confirmou o afastamento da amortização pelo sistema francês e determinou sua substituição pelo "cálculo de juros simples". Neste caso, diferente do que ocorreu com o julgado anterior em que o sistema para recálculo foi informado (sistema de Gauss), neste caso o Tribunal determinou apenas o recálculo a juros simples, cabendo, portanto, ao perito a realização da liquidação da sentença de acordo com algum sistema de amortização a juros simples, à sua escolha, desde que, evidentemente, seja fundamentada e que atenda aos critérios do julgado. Uma alternativa para o caso acima seria a realização do cálculo com base no sistema de equivalência a juros simples, discutido neste trabalho.

Os julgados evidenciam que o tema é recorrente, e a quantidade de novos processos envolvendo essa temática também confirma que as discussões ligadas ao sistema francês de amortização permanecerão, no Brasil, com a mesma intensidade.

Conforme discutido, são muitos os argumentos levantados pelas partes nas ações envolvendo contratos financeiros, o que exige do perito grande habilidade técnica para 
oferecer uma resposta adequada, contribuindo para tornar a controvérsia técnica compreensível para o Juízo, de forma que o processo possa ser julgado com segurança, visto que, nem sempre, o Juízo indica com precisão qual o sistema de amortização alternativo que o profissional deverá adotar, cabendo, nesses casos, a tomada de decisão com base no julgamento profissional.

Diante disso, e apresentados os principais elementos ligados à perícia contábil e à perícia contábil financeira, em seguida serão apresentados os procedimentos metodológicos da pesquisa e o estudo de caso a ser analisado.

\section{METODOLOGIA}

O presente estudo classifica-se como uma pesquisa aplicada que, segundo Vergara (2000, p. 47), é aquela "motivada pela necessidade de resolver problemas". Esta pesquisa trata de um estudo de caso em que se analisam dois sistemas de amortização em um contrato de financiamento real, com objetivo de resolver um dado problema, qual seja, o recálculo do contrato segundo uma metodologia alternativa ao sistema francês de amortização, com emprego de juros simples.

Quanto aos objetivos, a pesquisa é classificada como descritiva que, segundo Gil (1999), é aquela que tem como norte descrever as características de um determinado fenômeno. Neste estudo, busca-se descrever para melhor compreender os sistemas de amortização sob análise, visando pavimentar o caminho necessário para a análise da sentença e o recálculo do contrato a ser realizado.

Quanto aos procedimentos, classifica-se como estudo de caso que, segundo Gil (1999) é caracterizado pelo estudo profundo de um determinado objeto, visando obter conhecimentos amplos e profundos sobre ele. Nesta pesquisa, a análise do contrato sub judice configura-se como um estudo de caso, visto que toda a parte aplicada da pesquisa gira em torno de um único processo e um único contrato, embora os procedimentos empregados para realização dos cálculos e os achados possam ser aproveitados em outros casos similares.

Ainda quanto aos procedimentos, a pesquisa classifica-se como bibliográfica que, segundo Beuren (2003), tem o objetivo de recolher informações e conhecimentos prévios acerca de um problema para o qual se procura uma resposta. A pesquisa bibliográfica é parte obrigatória em qualquer tipo de estudo, haja vista que é por meio dela que se toma conhecimento sobre a produção científica previamente existente sobre o tema em estudo.

A pesquisa também classifica-se como documental. Segundo Gil (1999), a pesquisa documental baseia-se em materiais que não receberam um tratamento analítico. No caso desta pesquisa, a sentença, o contrato de financiamento, e o próprio processo judicial empregados no estudo de caso são classificados como documentos. Por essa razão, a pesquisa também é documental.

E por fim, quanto a abordagem do problema, a pesquisa classifica-se tanto como qualitativa quanto como quantitativa. A pesquisa qualitativa, segundo Beuren (2003), é aquela que promove análises mais profundas em relação ao fenômeno estudado, em geral não abordados em estudos quantitativos. Ou seja, na pesquisa qualitativa busca-se uma maior compreensão acerca do fenômeno estudado. Nesta pesquisa, não foram simplesmente apresentados de forma superficial os resultados e os cálculos da revisão do contrato, mas sim realizou-se análises mais detidas sobre os achados, foram realizadas comparações de valores e analisados os impactos dos números no patrimônio do mutuário, evidenciando uma análise que extrapola o meramente superficial, configurando, assim, a pesquisa como qualitativa.

Por sua vez, a pesquisa quantitativa também foi empregada visto que, para realização dos cálculos dos sistemas de amortização, empregou-se técnicas matemáticas rigorosas, 
configurando, assim, a pesquisa como quantitativa. Segundo Richardson (1999), a pesquisa quantitativa caracteriza-se pelo emprego de quantificação, seja na coleta ou no tratamento dos dados, configurando-se a pesquisa quantitativa com o emprego de técnicas simples, como a média simples, percentuais, desvio-padrão, ou de técnicas complexas, como a regressão.

Ainda segundo Richardson (1999), a pesquisa quantitativa é importante por garantir a precisão dos resultados, evitar distorções e garantir segurança nas inferências. No caso do presente estudo, como dito, os cálculos seguem equações matemáticas e protocolos quantitativos bem definidos, que desobedecidos podem comprometer completamente os resultados. Desta forma, a pesquisa também enquadra-se como quantitativa.

Sobre os sistemas de amortização a serem discutidos nesta pesquisa, a fundamentação matemática que embasa os procedimentos adotados são apresentados a seguir.

Segundo Sandrini (2007), o cálculo da prestação de um empréstimo ou financiamento amortizado pelo sistema francês se dá mediante o emprego da seguinte equação:

$$
P=C x \frac{(1+i)^{n} x i}{(1+i)^{n}-1}
$$

Em que:

$P=$ valor da prestação (a ser calculado)

$\mathrm{C}=$ valor do capital emprestado ou financiado

$\mathrm{i}=$ taxa de juros contratada

$\mathrm{n}$ = número de períodos em que o contrato será quitado

O sistema de equivalência a juros tem suas prestações constantes, calculadas, conforme Sandrini (2007), com base na seguinte equação:

$$
P=C \div\left[\frac{1}{\left(1+i \times n_{1}\right)}+\frac{1}{\left(1+i \times n_{2}\right)}+\cdots+\frac{1}{\left(1+i \times n_{k}\right)}\right]
$$

Em que:

$\mathrm{P}=$ valor da prestação (a ser calculado)

$\mathrm{C}=$ valor do capital emprestado ou financiado

$\mathrm{i}=$ taxa de juros contratada

$\mathrm{n}=$ número de períodos em que o contrato será quitado

Saliente-se que as equações empregadas, bem como os detalhamentos ligados aos cálculos realizados, comparações e demais análises são apresentados, em sua maioria, diretamente na seção 4, destinada à apresentação dos resultados, visto que se apresentadas nesta seção metodológica teriam que ser, necessariamente, resgatadas na seção seguinte. Portanto, por uma questão de conveniência, e para uma leitura mais fluida, todos esses aspectos técnicos serão mais bem detalhados na seção 4.

Apresentados os principais aspectos metodológicos da pesquisa, em seguida será feita uma breve exposição do caso a ser analisado, visto que é ele quem irá balizar as análises a serem realizadas na seção seguinte.

\subsection{SÍNTESE FÁTICO-PROCESSUAL, CONTRATUAL E ROTEIRO DE TRABALHO PERICIAL}

O contrato no 2012.00XX8-X9, em análise, é parte integrante do processo número 00XX95-X8.2016.805.01XX (os dados de identificação serão omitidos intencionalmente ao longo do trabalho), ajuizado na 9a Vara Cível e Comercial da Comarca de Salvador, Bahia, cujo 
autor da ação é J.S.F. e o réu o XX Financeira S/A. A ação foi proposta em 06/12/2016, o réu foi citado em 16/01/2017 e os principais fatos ligados à ação são expostos a seguir.

J.S.F. financiou junto à financeira, em 12/01/2012, a compra de um veículo Chevrolet Cobalt 1.4, pelo valor de $\mathrm{R} \$ 38.000,00$ (trinta e oito mil reais). O veículo foi $100 \%$ financiado, sem entrada, com o 10 pagamento para 30 dias, e as demais parcelas vencendo nos meses subsequentes. Da leitura do contrato, verifica-se que a taxa de juros praticada no financiamento é de 2,23\% a.m., e o contrato não faz menção a nenhum outro valor incluído no financiamento, como taxa de abertura de crédito ou qualquer outra, indicando tão somente no campo "valor financiado" o valor de $\mathrm{R} \$ 38.000,00$, relativo ao valor do veículo.

O prazo de financiamento indicado no contrato é de 60 (sessenta) meses, e não há indicação do sistema de amortização. $O$ contrato apenas informa que o veículo será pago em 60 prestações mensais, iguais e sucessivas de $R \$ 1.174,01$ (um mil, cento e setenta e quatro reais e um centavo) cada uma, a primeira com vencimento em 12/02/2012, ou seja, 30 dias após a assinatura do contrato, bem como as demais prestações com vencimento, cada uma, no dia 12 de cada mês.

O financiamento foi quitado por J.S.F. em 12/01/2017, com o pagamento da última prestação. Ocorre que em 06/12/2016, aproximadamente um mês antes da quitação, J.S.F. ajuizou ação revisional em face da XX Financeira S/A, requerendo, em síntese: a) a revisão do sistema de amortização contratual, eis que extremamente oneroso para o consumidor, visto que se trata do sistema de amortização conhecido como "Tabela Price", abusivo e não permitido pela legislação brasileira por gerar anatocismo, ou seja, juros sobre juros; b) o recálculo do contrato com base em um sistema de "juros simples", com devolução dos valores pagos a maior.

Realizada audiência de conciliação entre as partes, esta restou infrutífera. No despacho saneador, o Juiz dispensou a realização de audiência de instrução, visto que não havia pedido de oitiva por nenhuma das partes, bem como pelo fato de que, na opinião do Juízo, o conjunto de provas documentais carreado aos autos era suficiente para a prolação da sentença, sem necessidade da realização de novas audiências.

Desta forma, em 19/11/2018 foi prolatada a sentença nos autos, que em síntese: a) condenou a XX Financeira S/A a revisar o sistema de amortização do contrato, afastando a incidência da amortização com base no sistema francês (Tabela Price) e determinando o recálculo do contrato com base em sistema de "juros simples"; b) devolução dos valores pagos a maior pelo autor, devidamente corrigidos com base no IPCA/IBGE, acrescidos, ainda, de juros de 1\% a.m., com capitalização simples, a partir da citação do réu; c) custas e honorários advocatícios, estes arbitrados em $\mathrm{R} \$ 5.000,00$ (cinco mil reais), pelo réu.

Ato contínuo, o Juízo nomeou como perito o Sr. P.F.F. para realização dos cálculos de liquidação da sentença, com base nas disposições do julgado. Saliente-se que não foram juntados, nem pelas partes, nem pelo juízo, quesitos a serem respondidos pelo perito. Tal ausência de quesitos em casos como esse é comum, visto que, em síntese, o objetivo tanto do juízo quanto das partes é um só: saber o eventual valor devido pelo réu ao autor da ação, que necessariamente deverá ser apresentado pelo perito no laudo pericial, sob pena de fugir ao objeto da perícia designada pelo juízo.

Quando da seleção intencional desta sentença, o processo ainda estava na posse do perito, portanto, não havia sido juntado aos autos o laudo pericial contábil relativo ao processo. Portanto, partir deste ponto, todas as condutas descritas, os cálculos e demais procedimentos realizados foram os adotados pelo autor do trabalho, e não praticados pelo perito ou por outro ator processual. Feitas tais apresentações, na seção seguinte far-se-á a análise e discussão dos resultados. 


\section{ANÁLISE E DISCUSSÃO DOS RESULTADOS}

Inicialmente, repita-se o que já foi mencionado anteriormente que a escolha do processo em análise foi intencional, visto que se tratava de uma ação revisional, envolvendo a discussão do sistema francês de amortização, com sentença prolatada e sem laudo pericial juntado aos autos.

O primeiro ato para liquidação da sentença foi a realização da leitura completa dos autos, em especial do contrato, dos demais documentos juntados pelas partes no processo, e da sentença prolatada pelo Juiz, tarefa que demandou, aproximadamente, 5 (cinco) horas técnicas.

Em seguida, procedeu-se à digitação, em planilha do MS Excel, dos pagamentos realizados pelo autor ao longo do período do financiamento, com objetivo de verificar eventuais pagamentos em atraso para cálculo de juros ou outros encargos. Em nenhum dos 60 meses houve pagamento em atraso.

Conforme se verificou no processo, nas datas em que o vencimento da prestação ocorreu em sábados ou domingos, o autor algumas vezes antecipou, em outras postergou o pagamento para o dia útil subsequente. Portanto, os documentos juntados aos autos não evidenciam nenhum pagamento em atraso que pudesse ensejar a cobrança de juros ou outros encargos contratuais.

O próximo ato para realizar a liquidação da sentença na forma determinada pelo juízo foi a escolha do sistema de amortização juros simples. Conforme evidencia o excerto da sentença, anteriormente descrito, o juízo não indicou com precisão qual seria o sistema de amortização substituto ao sistema francês, determinando apenas o "recálculo do contrato com base em sistema de juros simples". Para este processo, adotou-se o recálculo do contrato com base no sistema de equivalência a juros simples (SEJS), porém, em uma situação real e desde que devidamente fundamentado, poderia o perito promover a liquidação da sentença com base em outro sistema de amortização a juros simples, desde que motivada sua escolha. No caso deste trabalho, optou-se pelo sistema de equivalência a juros simples pela farta literatura que o fundamenta, e por ser um sistema de amortização com razoável emprego, em casos como o ora analisado.

Conforme evidencia o contrato, o tomador pagou, pelo financiamento do veículo, 60 prestações de $\mathrm{R} \$ 1.174,01$, com uma taxa de juros de 2,23\% a.m.. É sempre recomendado promover a composição deste valor de prestação, de modo que o perito confirme se, de fato, a financeira empregou no cálculo da parcela a taxa indicada no contrato. Foi este o ato em seguida realizado. Para surpresa, a taxa informada em contrato não foi empregada no cálculo da prestação, conforme evidencia-se adiante.

Para o cálculo de formação da parcela (ou prestação) pelo sistema francês, empregouse a equação a seguir:

Em que:

$$
P=C \times \frac{(1+i)^{n} x i}{(1+i)^{n}-1}
$$

$\mathrm{P}=$ valor da prestação (a ser calculado)

$C=$ valor do capital emprestado ou financiado $(R \$ 38.000,00)$

$\mathrm{i}=$ taxa de juros contratada (2,23\% a.m., informada em contrato)

$\mathrm{n}$ = número de períodos em que o contrato será quitado (60 meses)

$$
P=38.000 x \frac{(1+0,0223)^{60} \times 0,0223}{(1+0,0223)^{60}-1} \gg P=R \$ 1.154,90
$$


Ou seja, empregando as informações contidas no contrato, a prestação mensal a ser paga pelo tomador deveria ser de $\mathrm{R} \$ 1.154,90$, e não $\mathrm{R} \$ 1.174,01$, que foi o valor mensal de cada uma das 60 prestações pagas pelo autor da ação. Para essa diferença tem-se duas alternativas que podem justificar o ocorrido: a) o banco incluiu algum outro valor "encoberto" no financiamento; b) o banco praticou taxa de juros diversa da contratada. Como o contrato indica expressamente que o valor financiado é de $\mathrm{R} \$ 38.000,00$, resta a alternativa de que o banco tenha praticado taxa diversa da contratada.

Para descobrir a real taxa utilizada pelo banco, aplicou-se a equação a seguir:

$$
q 0=\frac{1-(1+j)^{-n}}{j} p
$$

Onde:

$\mathrm{n}$ = número de períodos em que o contrato será quitado (60 meses)

$\mathrm{j}=$ taxa de juros procurada

$p=$ valor da prestação (informada no contrato: $R \$ 1.174,01$ )

q0 = valor financiado (informado no contrato: $\mathrm{R} \$ 38.000,00$ )

Nessa equação, o cálculo da taxa de juros (j) é feito por aproximação do valor da prestação ( $p)$, recursivamente, com margem de erro ínfima. Aplicadas as informações relativas ao contrato na equação acima, obtem-se que a taxa de juros aplicada ao mutuário, em realidade, foi de $2,3 \%$ a.m., e não 2,23\% a.m. conforme informado em contrato. Calculando a prestação com a taxa de juros efetivamente aplicada (conforme resultado da equação acima), obteve-se o valor de prestação de $\mathrm{R} \$ 1.174,01$, conforme abaixo demonstrado:

$$
P=38.000 x \frac{(1+0,023)^{60} \times 0,023}{(1+0,023)^{60}-1} \gg P=R \$ 1.174,01
$$

Não é possível afirmar se a financeira errou ao realizar o cálculo da prestação (pois se tratam de valores parecidos: $2,23 \%$ e 2,3\%) ou se agiu de má-fé. Fato é que, na perícia, uma vez identificada essa circunstância, cabe ao perito mencionar tal fato no laudo, alertando o juízo do achado, e dar seguimento aos trabalhos.

A título meramente ilustrativo, apresenta-se na Tabela 1 um excerto da comparação entre a prestação paga pelo mutuário $(\mathrm{R} \$ 1.174,01)$ e a que deveria ter sido paga segundo as

\begin{tabular}{|c|c|c|c|}
\hline Prestação & V. Pago & V. Correto & Dif. Mensal \\
\hline 1 & $\mathrm{R} \$ 1,174.01$ & $R \$ 1,154.90$ & $\mathrm{R} \$ 19.11$ \\
\hline 2 & $\mathrm{R} \$ 1,174.01$ & $\mathrm{R} \$ 1,154.90$ & $\mathrm{R} \$ 19.11$ \\
\hline 3 & $\mathrm{R} \$ 1,174.01$ & $\mathrm{R} \$ 1,154.90$ & $\mathrm{R} \$ 19.11$ \\
\hline 4 & $\mathrm{R} \$ 1,174.01$ & $R \$ 1,154.90$ & $\mathrm{R} \$ 19.11$ \\
\hline 5 & $\mathrm{R} \$ 1,174.01$ & $\mathrm{R} \$ 1,154.90$ & $\mathrm{R} \$ 19.11$ \\
\hline 6 & $\mathrm{R} \$ 1,174.01$ & $\mathrm{R} \$ 1,154.90$ & $\mathrm{R} \$ 19.11$ \\
\hline 7 & $\mathrm{R} \$ 1,174.01$ & $R \$ 1,154.90$ & $\mathrm{R} \$ 19.11$ \\
\hline 8 & $\mathrm{R} \$ 1,174.01$ & $\mathrm{R} \$ 1,154.90$ & $\mathrm{R} \$ 19.11$ \\
\hline 9 & $\mathrm{R} \$ 1,174.01$ & $\mathrm{R} \$ 1,154.90$ & $\mathrm{R} \$ 19.11$ \\
\hline 10 & $\mathrm{R} \$ 1,174.01$ & $\mathrm{R} \$ 1,154.90$ & $\mathrm{R} \$ 19.11$ \\
\hline$\ldots$ & $\ldots$ & $\ldots$ & $\ldots$ \\
\hline 60 & $\mathrm{R} \$ 1,174.01$ & $\mathrm{R} \$ 1,154.90$ & $\mathrm{R} \$ 19.11$ \\
\hline TOTAL & $\mathrm{R} \$ \quad 70,440.60$ & $\mathrm{R} \$ \quad 69,294.00$ & $\mathrm{R} \$ \quad 1,146.60$ \\
\hline
\end{tabular}
informações contratuais ( $R \$ 1.154,90)$, bem como a diferença resultante:

Fonte: dados da pesquisa (2019) 
Conforme se verifica na Tabela 1, os valores pagos a maior pelo mutuário, decorrentes do erro no cálculo da prestação, sem qualquer correção, somam $\mathrm{R} \$ 1.146,60$ (valor principal). No entanto, não é este o valor a ser encontrado, mas sim as diferenças decorrentes da mudança no sistema de amortização contratual, que serão apresentadas adiante.

Antes, porém, mesmo que tal informação não constitua ato essencial na perícia, é interessante apresentar o demonstrativo de amortização e evolução da dívida no sistema francês. Para isso, é necessário calcular, além do valor da prestação, as amortizações e o valor dos juros do financiamento.

A amortização, no sistema francês, é calculada pela diferença entre o valor dos juros e o valor da prestação mensal. Como já mencionado, o sistema de amortização francês possui como um dos seus pressupostos que as prestações são constantes. No caso em análise, as prestações efetivamente cobradas do mutuário foram de $R \$ 1.174,01$ (considerando a taxa de juros que foi efetivamente praticada pela financeira), enquanto que o valor dos juros é calculado pela aplicação da taxa de juros (neste caso, a taxa aplicada pela financeira foi de $2,3 \%$ a.m., e não $2,23 \%$ a.m. conforme constou em contrato) sobre o saldo devedor contratual, que para fins da prestação de número 1 era de $\mathrm{R} \$ 38.000,00$ (valor financiado).

Portanto, o valor dos juros na 1 ạ prestação é de $\mathrm{R} \$ 874,00$, assim calculado:

$$
J=S D \times i \gg J=R \$ 38.000,00 \times 0,023 \gg J=R \$ 874,00
$$

Em que:

$\mathrm{J}=$ valor dos juros

$\mathrm{SD}=$ saldo devedor do contrato

$\mathrm{i}=$ taxa de juros praticada

Logo, a amortização desta 1á prestação é dada pela diferença entre o valor da prestação ( $R \$ 1.174,01)$ e o valor dos juros ( $R \$ 874,00$ ), resultando no valor de $R \$ 300,01$. Como o saldo devedor e os juros decrescem mês a mês nesse sistema de amortização, a amortização é crescente. Na Tabela 2 apresenta-se a evolução da dívida do financiamento.

Tabela 2 - evolução do financiamento no sistema francês de amortização

\begin{tabular}{|c|c|c|c|c|c|c|}
\hline $\mathbf{P}$ & Juros & & Amortização & Prestação & \multicolumn{2}{|c|}{ Saldo Devedor } \\
\hline 0 & & & & & $\mathrm{RS}$ & $38,000.00$ \\
\hline 1 & $\mathrm{R} \$ \mathbf{8 7 4 . 0 0}$ & $\mathrm{R} \$$ & 300.01 & $\mathrm{R} \$ \quad 1,174.01$ & $\mathrm{R} \$$ & $37,699.99$ \\
\hline 2 & $\mathrm{R} \$ \quad 867.10$ & $\mathrm{R} \$$ & 306.91 & $\mathrm{R} \$ \quad 1,174.01$ & $\mathrm{R} \$$ & $37,393.08$ \\
\hline 3 & $\mathrm{R} \$ \mathbf{8 6 0 . 0 4}$ & $\mathrm{R} \$$ & 313.97 & $\mathrm{R} \$ 1,174.01$ & $\mathrm{RS}$ & $37,079.11$ \\
\hline 4 & $\mathrm{R} \$ \mathbf{8 5 2 . 8 2}$ & $\mathrm{R} \$$ & 321.19 & $\mathrm{R} \$ \quad 1,174.01$ & $\mathrm{R} \$$ & $36,757.92$ \\
\hline 5 & $\mathrm{R} \$ \quad 845.43$ & $\mathrm{R} \$$ & 328.58 & $\mathrm{R} \$ \quad 1,174.01$ & $\mathrm{R} \$$ & $36,429.34$ \\
\hline 6 & $\mathrm{R} \$ \mathbf{8 3 7 . 8 7}$ & $\mathrm{R} \$$ & 336.14 & $\mathrm{R} \$ 1,174.01$ & $\mathrm{R} \$$ & $36,093.21$ \\
\hline 7 & $\mathrm{R} \$ \mathbf{8 3 0 . 1 4}$ & $\mathrm{R} \$$ & 343.87 & $\mathrm{R} \$ 1,174.01$ & $\mathrm{R} \$$ & $35,749.34$ \\
\hline 8 & $\mathrm{R} \$ \quad 822.23$ & $\mathrm{R} \$$ & 351.78 & $\mathrm{R} \$ 1,174.01$ & $\mathrm{R} \$$ & $35,397.57$ \\
\hline 9 & $\mathrm{R} \$ \mathbf{8 1 4 . 1 4}$ & $\mathrm{R} \$$ & 359.87 & $\mathrm{R} \$ \quad 1,174.01$ & $\mathrm{R} \$$ & $35,037.70$ \\
\hline 10 & $\mathrm{R} \$ \quad 805.87$ & $\mathrm{R} \$$ & 368.14 & $\mathrm{R} \$ \quad 1,174.01$ & $\mathrm{RS}$ & $34,669.56$ \\
\hline 11 & $\mathrm{R} \$ \mathbf{7} 797.40$ & $\mathrm{R} \$$ & 376.61 & $\mathrm{R} \$ \quad 1,174.01$ & $\mathrm{R} \$$ & $34,292.95$ \\
\hline 12 & $\mathrm{R} \$ 788.74$ & $\mathrm{R} \$$ & 385.27 & $\mathrm{R} \$ \mathbf{1} 174.01$ & $\mathrm{RS}$ & $33,907.67$ \\
\hline 13 & $\mathrm{R} \$ 779.88$ & $\mathrm{R} \$$ & 394.13 & $\mathrm{R} \$ \quad 1,174.01$ & $\mathrm{R} \$$ & $33,513.54$ \\
\hline 14 & $\mathrm{R} \$ \quad 770.81$ & $\mathrm{R} \$$ & 403.20 & $\mathrm{R} \$ \quad 1,174.01$ & $\mathrm{R} \$$ & $33,110.34$ \\
\hline 15 & $\mathrm{R} \$ 761.54$ & $\mathrm{R} \$$ & 412.47 & $\mathrm{R} \$ 1,174.01$ & $\mathrm{RS}$ & $32,697.87$ \\
\hline 16 & $\mathrm{R} \$ \mathbf{7} 752.05$ & $\mathrm{R} \$$ & 421.96 & $\mathrm{R} \$ \quad 1,174.01$ & $\mathrm{R} \$$ & $32,275.91$ \\
\hline 17 & $\mathrm{R} \$ \mathbf{7 4 2 . 3 5}$ & $\mathrm{R} \$$ & 431.66 & $\mathrm{R} \$ \quad 1,174.01$ & $\mathrm{R} \$$ & $31,844.25$ \\
\hline 18 & $\mathrm{R} \$ 732.42$ & $\mathrm{R} \$$ & 441.59 & $\mathrm{R} \$ 1,174.01$ & $\mathrm{RS}$ & $31,402.65$ \\
\hline 19 & $\mathrm{R} \$ 722.26$ & $\mathrm{R} \$$ & 451.75 & $\mathrm{R} \$ \quad 1,174.01$ & $\mathrm{R} \$$ & $30,950.91$ \\
\hline 20 & $\mathrm{R} \$ \mathbf{7 1 1 . 8 7}$ & $\mathrm{R} \$$ & 462.14 & $\mathrm{R} \$ \quad 1,174.01$ & $\mathrm{R} \$$ & $30,488.77$ \\
\hline 21 & $\mathrm{R} \$ \mathbf{7} 701.24$ & $\mathrm{R} \$$ & 472.77 & $\mathrm{R} \$ \quad 1,174.01$ & $\mathrm{R} \$$ & $30,016.00$ \\
\hline 22 & $\mathrm{R} \$ \quad 690.37$ & $\mathrm{R} \$$ & 483.64 & 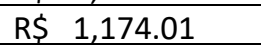 & $\mathrm{R} \$$ & $29,532.36$ \\
\hline 23 & $\mathrm{R} \$ \quad 679.24$ & $\mathrm{R} \$$ & 494.77 & $\mathrm{R} \$ 1,174.01$ & $\mathrm{R} \$$ & $29,037.59$ \\
\hline 24 & $\mathrm{R} \$ \quad 667.86$ & $\mathrm{R} \$$ & 506.15 & $\mathrm{R} \$ 1,174.01$ & $\mathrm{R} \$$ & $28,531.45$ \\
\hline
\end{tabular}




\begin{tabular}{|c|c|c|c|c|c|c|}
\hline 25 & $\mathrm{R} \$ \quad 656.22$ & $\mathrm{R} \$$ & 517.79 & $\mathrm{R} \$ \mathbf{1} \quad 174.01$ & $\mathrm{R} \$$ & $28,013.66$ \\
\hline 26 & $\mathrm{R} \$ \quad 644.31$ & $\mathrm{R} \$$ & 529.70 & $\mathrm{R} \$ \quad 1,174.01$ & $\mathrm{R} \$$ & $27,483.96$ \\
\hline 27 & $\mathrm{R} \$ 632.13$ & $\mathrm{R} \$$ & 541.88 & $\mathrm{R} \$ \quad 1,174.01$ & $\mathrm{R} \$$ & $26,942.08$ \\
\hline 28 & $\mathrm{R} \$ \mathbf{6 1 9 . 6 7}$ & $\mathrm{R} \$$ & 554.34 & $\mathrm{R} \$ \quad 1,174.01$ & $\mathrm{R} \$$ & $26,387.74$ \\
\hline 29 & $\mathrm{R} \$ \quad 606.92$ & $\mathrm{R} \$$ & 567.09 & $\mathrm{R} \$ 1,174.01$ & $\mathrm{RS}$ & $25,820.65$ \\
\hline 30 & $\mathrm{R} \$ 593.87$ & $\mathrm{R} \$$ & 580.14 & $\mathrm{R} \$ 1,174.01$ & $\mathrm{R} \$$ & $25,240.51$ \\
\hline 31 & $\mathrm{R} \$ \quad 580.53$ & $\mathrm{R} \$$ & 593.48 & $\mathrm{R} \$ 1,174.01$ & $\mathrm{R} \$$ & $24,647.04$ \\
\hline 32 & $\mathrm{R} \$ \quad 566.88$ & $\mathrm{R} \$$ & 607.13 & $\mathrm{R} \$ \quad 1,174.01$ & $\mathrm{R} \$$ & $24,039.91$ \\
\hline 33 & $\mathrm{R} \$ 552.92$ & $\mathrm{R} \$$ & 621.09 & $\mathrm{R} \$ 1,174.01$ & $\mathrm{R} \$$ & $23,418.82$ \\
\hline 34 & $\mathrm{R} \$ 538.63$ & $\mathrm{R} \$$ & 635.38 & $\mathrm{R} \$ \quad 1,174.01$ & $\mathrm{RS}$ & $22,783.44$ \\
\hline 35 & $\mathrm{R} \$ \quad 524.02$ & $\mathrm{R} \$$ & 649.99 & $\mathrm{R} \$ \quad 1,174.01$ & $\mathrm{R} \$$ & $22,133.45$ \\
\hline 36 & $\mathrm{R} \$ 509.07$ & $\mathrm{RS}$ & 664.94 & $\mathrm{R} \$ 1,174.01$ & $\mathrm{R} \$$ & $21,468.51$ \\
\hline 37 & $\mathrm{R} \$ 493.78$ & $\mathrm{R} \$$ & 680.23 & $\mathrm{R} \$ \quad 1,174.01$ & $\mathrm{R} \$$ & $20,788.27$ \\
\hline 38 & $\mathrm{R} \$ \quad 478.13$ & $\mathrm{R} \$$ & 695.88 & $\mathrm{R} \$ \quad 1,174.01$ & $\mathrm{R} \$$ & $20,092.39$ \\
\hline 39 & $\mathrm{R} \$ \quad 462.13$ & $\mathrm{RS}$ & 711.88 & $\mathrm{R} \$ \quad 1,174.01$ & $\mathrm{RS}$ & $19,380.51$ \\
\hline 40 & $\mathrm{R} \$ \mathbf{4} 445.75$ & $\mathrm{R} S$ & 728.26 & 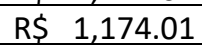 & $\mathrm{R} \$$ & $18,652.25$ \\
\hline 41 & $\mathrm{R} \$ \quad 429.00$ & $\mathrm{R} \$$ & 745.01 & $\mathrm{R} \$ 1,174.01$ & $\mathrm{RS}$ & $17,907.24$ \\
\hline 42 & $\mathrm{R} \$ \quad 411.87$ & $\mathrm{R} \$$ & 762.14 & $\mathrm{R} \$ \quad 1,174.01$ & $\mathrm{R} \$$ & $17,145.10$ \\
\hline 43 & $\mathrm{R} \$ 394.34$ & $\mathrm{R} \$$ & 779.67 & $\mathrm{R} \$ 1_{1,174.01}$ & $\mathrm{R} \$$ & $16,365.43$ \\
\hline 44 & $\mathrm{R} \$ 376.40$ & $\mathrm{R} \$$ & 797.61 & $\mathrm{R} \$ \quad 1,174.01$ & $\mathrm{R} \$$ & $15,567.82$ \\
\hline 45 & $\mathrm{R} \$ 358.06$ & $\mathrm{R} \$$ & 815.95 & $\mathrm{R} \$ \quad 1,174.01$ & $\mathrm{R} \$$ & $14,751.87$ \\
\hline 46 & $\mathrm{R} \$ 339.29$ & $\mathrm{R} S$ & 834.72 & $\mathrm{R} \$ \mathrm{~N}^{1,174.01}$ & $\mathrm{R} \$$ & $13,917.15$ \\
\hline 47 & $\mathrm{R} \$ 320.09$ & $\mathrm{R} \$$ & 853.92 & $\mathrm{R} \${ }^{\prime} \quad 1,174.01$ & $\mathrm{RS}$ & $13,063.24$ \\
\hline 48 & $\mathrm{R} \$ 300.45$ & $\mathrm{R} \$$ & 873.56 & $\mathrm{R} \$ 1,174.01$ & $\mathrm{R} \$$ & $12,189.68$ \\
\hline 49 & $\mathrm{R} \$ 280.36$ & $\mathrm{R} S$ & 893.65 & $\mathrm{R} \$ 1,174.01$ & $\mathrm{R} \$$ & $11,296.04$ \\
\hline 50 & $\mathrm{R} \$ \mathbf{2 5 9 . 8 1}$ & $\mathrm{R} \$$ & 914.20 & $\mathrm{R} \$ \quad 1,174.01$ & $\mathrm{R} \$$ & $10,381.83$ \\
\hline 51 & $\mathrm{R} \$ 238.78$ & $\mathrm{R} \$$ & 935.23 & $\mathrm{R} \$ 1,174.01$ & $\mathrm{R} \$$ & $9,446.61$ \\
\hline 52 & $\mathrm{R} \$ 217.27$ & $\mathrm{R} S$ & 956.74 & $\mathrm{R} \$ 1_{1,174.01}$ & $\mathrm{R} \$$ & $8,489.87$ \\
\hline 53 & $\mathrm{R} \$ 195.27$ & $\mathrm{R} \$$ & 978.74 & $\mathrm{R} \$ 1,174.01$ & $\mathrm{RS}$ & $7,511.13$ \\
\hline 54 & $\mathrm{R} \$ 172.76$ & $\mathrm{R} \$$ & $1,001.25$ & $\mathrm{R} \$ 1,174.01$ & $\mathrm{R} \$$ & $6,509.87$ \\
\hline 55 & $\mathrm{R} \$ 149.73$ & $\mathrm{R} \$$ & $1,024.28$ & 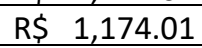 & $\mathrm{RS}$ & $5,485.59$ \\
\hline 56 & $\mathrm{R} \$ 126.17$ & $\mathrm{R} \$$ & $1,047.84$ & $\mathrm{R} \$ 1,174.01$ & $\mathrm{RS}$ & $4,437.75$ \\
\hline 57 & $\mathrm{R} \$ 102.07$ & $\mathrm{R} \$$ & $1,071.94$ & $\mathrm{R} \$ \quad 1,174.01$ & $\mathrm{R} \$$ & $3,365.80$ \\
\hline 58 & $\mathrm{R} \$ \mathbf{7 7 . 4 1}$ & $\mathrm{R} \$$ & $1,096.60$ & $\mathrm{R} \$ \quad 1,174.01$ & $\mathrm{R} \$$ & $2,269.21$ \\
\hline 59 & $\mathrm{R} \$ \quad 52.19$ & $\mathrm{R} \$$ & $1,121.82$ & $\mathrm{R} \$ \quad 1,174.01$ & $\mathrm{RS}$ & $1,147.39$ \\
\hline 60 & $\mathrm{R} \$ 26.39$ & $\mathrm{R} \$$ & $1,147.39$ & $\mathrm{R} \$ \quad 1,174.01$ & $\mathrm{RS}$ & - \\
\hline
\end{tabular}

Portanto, feito o cálculo da prestação inicial (em que se constatou, neste caso, erro da financeira no tocante à taxa de juros empregada) e apresentada a evolução do financiamento no sistema francês de amortização, em seguida realizou-se o recálculo do financiamento, com base no sistema de equivalência a juros simples (SEJS).

O primeiro passo desta etapa é calcular o valor da prestação no SEJS, que assim como no sistema francês de amortização, é constante. A equação a seguir é empregada nesta tarefa.

Em que:

$$
P=C \div\left[\frac{1}{\left(1+i \times n_{1}\right)}+\frac{1}{\left(1+i \times n_{2}\right)}+\cdots+\frac{1}{\left(1+i \times n_{k}\right)}\right]
$$

$\mathrm{P}=$ valor da prestação (a ser calculado)

$\mathrm{C}=$ valor do capital emprestado ou financiado ( $\mathrm{R} \$ 38.000,00)$

$\mathrm{i}$ = taxa de juros contratada (2,23\% a.m.. Aqui usa-se a taxa efetivamente contratada, visto que não faz sentido utilizar a taxa de $2,3 \%$ a.m., empregada pela financeira, pois não foi esta a taxa contratada)

$\mathrm{n}$ = número de períodos em que o contrato será quitado (60 meses)

Substituindo os valores na equação tem-se: 


$$
\begin{gathered}
P=38.000 \div\left[\frac{1}{(1+0,0223 \times 1)}+\frac{1}{(1+0,0223 \times 2)}+\cdots+\frac{1}{(1+0,0223 \times 60)}\right] \\
P=38.000 \div\left[\frac{1}{(1,0223)}+\frac{1}{(1,0446)}+\cdots+\frac{1}{(2,338)}\right] \\
P=38.000 \div 37,80039 \gg P=R \$ 1.005,28
\end{gathered}
$$

Destaca-se que o valor da prestação anteriormente calculada também pode ser encontrada mediante emprego da seguinte equação:

$$
P=C x\left[\frac{1}{\left(1+i \times n_{1}\right)}+\frac{1}{\left(1+i \times n_{2}\right)}+\cdots+\frac{1}{\left(1+i \times n_{k}\right)}\right]^{-n}
$$

Empregando os mesmos valores ter-se-ia:

$P=38.000 x[37,80039]^{-60} \gg P=38.000 \times 0,026455 \gg P=R \$ 1.005,28$

Portanto, tem-se que cada uma das 60 prestações no sistema de equivalência a juros simples será de $\mathrm{R} \$ 1.005,28$. Resta agora calcular o valor dos juros e da amortização em cada uma das prestações. A amortização, neste sistema, é dada por:

$$
A_{1}=\frac{P}{\left(1+i \times n_{1}\right)} ; A_{2}=\frac{P}{\left(1+i \times n_{2}\right)} \ldots A_{n}=\frac{P}{\left(1+i \times n_{k}\right)}
$$

A amortização da 1ạ prestação é dada por:

$$
A_{1}=\frac{P}{\left(1+i \times n_{1}\right)} \gg A_{1}=\frac{1.005,28}{(1+0,0223 \times 1)} \gg A_{1}=\frac{1.005,28}{(1,0223)} \gg A_{1}=R \$ 983,35
$$

O valor dos juros no SEJS é dado pela diferença entre o valor da prestação (R\$1.005,28) e o valor de cada uma das amortizações ( $R \$ 983,35$ na 1 à prestação). Nesse caso, os juros da 1a prestação são de $\mathrm{R} \$ 21,93$. A amortização da $2^{a}$ prestação é dada por:

$$
A_{2}=\frac{P}{\left(1+i \times n_{2}\right)} \gg A_{2}=\frac{1.005,28}{(1+0,0223 \times 2)} \gg A_{2}=\frac{1.005,28}{(1,0446)} \gg A_{2}=R \$ 962,36
$$

Os juros da 2a prestação são de $R \$ 42,92$ ( $R \$ 1.005,28$ - R\$ 962,36). Com isso, apresenta-se a evolução do financiamento no sistema de equivalência a juros simples (SEJS), conforme Tabela 3.

Tabela 3 - evolução do financiamento no sistema de equivalência a juros simples

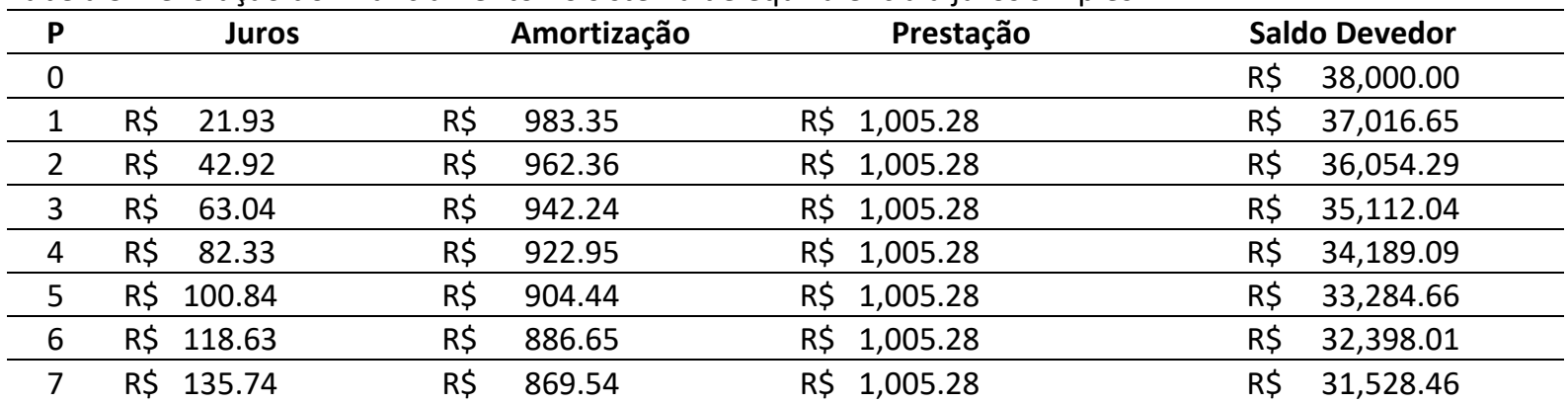




\begin{tabular}{|c|c|c|c|c|c|c|c|}
\hline 8 & $\mathrm{R} \$ 152.19$ & $\mathrm{R} \$$ & 853.09 & $\mathrm{R} \$$ & $1,005.28$ & $\mathrm{R} \$$ & $30,675.37$ \\
\hline 9 & $\mathrm{R} \$ 168.03$ & $\mathrm{R} \$$ & 837.25 & $\mathrm{R} \$$ & $1,005.28$ & $\mathrm{R} \$$ & $29,838.13$ \\
\hline 10 & $\mathrm{R} \$ 183.30$ & $\mathrm{R} \$$ & 821.98 & $\mathrm{R} \$$ & $1,005.28$ & $\mathrm{R} \$$ & $29,016.15$ \\
\hline 11 & $\mathrm{R} \$ 198.02$ & $\mathrm{RS}$ & 807.26 & $\mathrm{R} \$$ & $1,005.28$ & $\mathrm{R} \$$ & $28,208.89$ \\
\hline 12 & $\mathrm{R} \$ 212.22$ & $\mathrm{R} \$$ & 793.06 & $\mathrm{R} \$$ & $1,005.28$ & $\mathrm{R} \$$ & $27,415.83$ \\
\hline 13 & $\mathrm{R} \$ 225.93$ & $\mathrm{R} \$$ & 779.35 & $\mathrm{R} \$$ & $1,005.28$ & $\mathrm{R} \$$ & $26,636.48$ \\
\hline 14 & R\$ 239.18 & $\mathrm{R} \$$ & 766.10 & $\mathrm{RS}$ & $1,005.28$ & $\mathrm{R} \$$ & $25,870.38$ \\
\hline 15 & $\mathrm{R} \$ 251.98$ & $\mathrm{R} \$$ & 753.30 & $\mathrm{RS}$ & $1,005.28$ & $\mathrm{R} \$$ & $25,117.08$ \\
\hline 16 & $\mathrm{R} \$ 264.36$ & $\mathrm{R} \$$ & 740.92 & $\mathrm{RS}$ & $1,005.28$ & $\mathrm{R} \$$ & $24,376.16$ \\
\hline 17 & $\mathrm{R} \$ 276.34$ & $\mathrm{RS}$ & 728.94 & $\mathrm{RS}$ & $1,005.28$ & $\mathrm{R} \$$ & $23,647.22$ \\
\hline 18 & $\mathrm{R} \$ 287.94$ & $\mathrm{RS}$ & 717.34 & $\mathrm{R} \$$ & $1,005.28$ & $\mathrm{R} \$$ & $22,929.88$ \\
\hline 19 & $\mathrm{R} \$ 299.18$ & $\mathrm{RS}$ & 706.10 & $\mathrm{RS}$ & $1,005.28$ & $\mathrm{R} \$$ & $22,223.78$ \\
\hline 20 & $\mathrm{R} \$ 310.07$ & $\mathrm{RS}$ & 695.21 & $\mathrm{R} \$$ & $1,005.28$ & $\mathrm{R} \$$ & $21,528.56$ \\
\hline 21 & $\mathrm{R} \$ 320.62$ & $\mathrm{RS}$ & 684.66 & $\mathrm{R} \$$ & $1,005.28$ & $\mathrm{R} \$$ & $20,843.90$ \\
\hline 22 & $\mathrm{R} \$ 330.87$ & $\mathrm{RS}$ & 674.41 & $\mathrm{R} \$$ & $1,005.28$ & $\mathrm{R} \$$ & $20,169.49$ \\
\hline 23 & $\mathrm{R} \$ 340.81$ & $\mathrm{RS}$ & 664.47 & $\mathrm{R} \$$ & $1,005.28$ & $\mathrm{R} \$$ & $19,505.02$ \\
\hline 24 & $\mathrm{R} \$ 350.46$ & $\mathrm{R} \$$ & 654.82 & $\mathrm{R} \$$ & $1,005.28$ & $\mathrm{R} \$$ & $18,850.20$ \\
\hline 25 & $\mathrm{R} \$ 359.84$ & $\mathrm{RS}$ & 645.44 & $\mathrm{RS}$ & $1,005.28$ & $\mathrm{R} \$$ & $18,204.75$ \\
\hline 26 & $\mathrm{R} \$ 368.95$ & $\mathrm{RS}$ & 636.33 & $\mathrm{RS}$ & $1,005.28$ & $\mathrm{R} \$$ & $17,568.42$ \\
\hline 27 & $\mathrm{R} \$ 377.80$ & $\mathrm{R} \$$ & 627.48 & $\mathrm{RS}$ & $1,005.28$ & $\mathrm{R} \$$ & $16,940.94$ \\
\hline 28 & $\mathrm{R} \$ 386.42$ & $\mathrm{R} \$$ & 618.86 & $\mathrm{RS}$ & $1,005.28$ & $\mathrm{R} \$$ & $16,322.08$ \\
\hline 29 & $\mathrm{R} \$ 394.80$ & $\mathrm{R} \$$ & 610.48 & $\mathrm{RS}$ & $1,005.28$ & $\mathrm{R} \$$ & $15,711.60$ \\
\hline 30 & $\mathrm{R} \$ 402.95$ & $\mathrm{R} \$$ & 602.33 & $\mathrm{R} \$$ & $1,005.28$ & $\mathrm{R} \$$ & $15,109.27$ \\
\hline 31 & $\mathrm{R} \$ \quad 410.90$ & $\mathrm{R} \$$ & 594.38 & $\mathrm{R} \$$ & $1,005.28$ & $\mathrm{R} \$$ & $14,514.89$ \\
\hline 32 & $\mathrm{R} \$ 418.63$ & $\mathrm{RS}$ & 586.65 & $\mathrm{RS}$ & $1,005.28$ & $\mathrm{R} \$$ & $13,928.24$ \\
\hline 33 & $\mathrm{R} \$ \mathbf{4} 426.17$ & $\mathrm{R} \$$ & 579.11 & $\mathrm{R} \$$ & $1,005.28$ & $\mathrm{R} \$$ & $13,349.13$ \\
\hline 34 & $\mathrm{R} \$ 433.51$ & $\mathrm{R} \$$ & 571.77 & $\mathrm{R} \$$ & $1,005.28$ & $\mathrm{R} \$$ & $12,777.36$ \\
\hline 35 & $\mathrm{R} \$ \quad 440.67$ & $\mathrm{R} \$$ & 564.61 & $\mathrm{R} \$$ & $1,005.28$ & $\mathrm{R} \$$ & $12,212.76$ \\
\hline 36 & $\mathrm{R} \$ \quad 447.66$ & $\mathrm{RS}$ & 557.62 & $\mathrm{R} \$$ & $1,005.28$ & $\mathrm{R} \$$ & $11,655.13$ \\
\hline 37 & $\mathrm{R} \$ \quad 454.47$ & $\mathrm{R} \$$ & 550.81 & $\mathrm{R} \$$ & $1,005.28$ & $\mathrm{R} \$$ & $11,104.33$ \\
\hline 38 & $\mathrm{R} \$ \quad 461.12$ & $\mathrm{R} \$$ & 544.16 & $\mathrm{R} \$$ & $1,005.28$ & $\mathrm{R} \$$ & $10,560.17$ \\
\hline 39 & $\mathrm{R} \$ 467.61$ & $\mathrm{RS}$ & 537.67 & $\mathrm{R} \$$ & $1,005.28$ & $\mathrm{R} \$$ & $10,022.50$ \\
\hline 40 & $\mathrm{R} \$ \quad 473.95$ & $\mathrm{RS}$ & 531.33 & $\mathrm{RS}$ & $1,005.28$ & $\mathrm{R} \$$ & $9,491.16$ \\
\hline 41 & $\mathrm{R} \$ \quad 480.14$ & $\mathrm{R} \$$ & 525.14 & $\mathrm{R} \$$ & $1,005.28$ & $\mathrm{R} \$$ & $8,966.02$ \\
\hline 42 & $\mathrm{R} \$ 486.18$ & $\mathrm{R} \$$ & 519.10 & $\mathrm{RS}$ & $1,005.28$ & $\mathrm{R} \$$ & $8,446.93$ \\
\hline 43 & $\mathrm{R} \$ 492.09$ & $\mathrm{R} \$$ & 513.19 & $\mathrm{RS}$ & $1,005.28$ & $\mathrm{R} \$$ & $7,933.74$ \\
\hline 44 & $\mathrm{R} \$ \mathbf{4 9 7 . 8 7}$ & $\mathrm{R} \$$ & 507.41 & $\mathrm{R} \$$ & $1,005.28$ & $\mathrm{R} \$$ & $7,426.33$ \\
\hline 45 & $\mathrm{R} \$ 503.52$ & $\mathrm{R} \$$ & 501.76 & $\mathrm{R} \$$ & $1,005.28$ & $\mathrm{R} \$$ & $6,924.57$ \\
\hline 46 & $\mathrm{R} \$ 509.04$ & $\mathrm{R} \$$ & 496.24 & $\mathrm{R} \$$ & $1,005.28$ & $\mathrm{R} \$$ & $6,428.33$ \\
\hline 47 & $\mathrm{R} \$ 514.44$ & $\mathrm{RS}$ & 490.84 & $\mathrm{RS}$ & $1,005.28$ & $\mathrm{R} \$$ & $5,937.49$ \\
\hline 48 & $\mathrm{R} \$ 519.73$ & $\mathrm{R} \$$ & 485.55 & $\mathrm{R} \$$ & $1,005.28$ & $\mathrm{R} \$$ & $5,451.94$ \\
\hline 49 & $\mathrm{R} \$ 524.91$ & $\mathrm{RS}$ & 480.37 & $\mathrm{RS}$ & $1,005.28$ & $\mathrm{R} \$$ & $4,971.57$ \\
\hline 50 & $\mathrm{R} \$ 529.97$ & $\mathrm{RS}$ & 475.31 & $\mathrm{R} \$$ & $1,005.28$ & $\mathrm{R} \$$ & $4,496.26$ \\
\hline 51 & $\mathrm{R} \$ 534.93$ & $R \$$ & 470.35 & $\mathrm{RS}$ & $1,005.28$ & $\mathrm{R} \$$ & $4,025.91$ \\
\hline 52 & $\mathrm{R} \$ 539.79$ & $R \$$ & 465.49 & $R \$$ & $1,005.28$ & $\mathrm{R} \$$ & $3,560.41$ \\
\hline 53 & $\mathrm{R} \$ 544.54$ & $R \$$ & 460.74 & $R \$$ & $1,005.28$ & $\mathrm{R} \$$ & $3,099.68$ \\
\hline 54 & $\mathrm{R} \$ \quad 549.20$ & $\mathrm{R} \$$ & 456.08 & $\mathrm{RS}$ & $1,005.28$ & $\mathrm{R} \$$ & $2,643.60$ \\
\hline 55 & R\$ 553.77 & $\mathrm{R} \$$ & 451.51 & $\mathrm{RS}$ & $1,005.28$ & $\mathrm{R} \$$ & $2,192.10$ \\
\hline 56 & $\mathrm{R} \$ 558.25$ & $\mathrm{R} \$$ & 447.03 & $\mathrm{R} \$$ & $1,005.28$ & $\mathrm{R} \$$ & $1,745.07$ \\
\hline 57 & $\mathrm{R} \$ \quad 562.64$ & $\mathrm{R} \$$ & 442.64 & $\mathrm{RS}$ & $1,005.28$ & $\mathrm{R} \$$ & $1,302.43$ \\
\hline 58 & $\mathrm{R} \$ \mathbf{5 6 6 . 9 4}$ & $\mathrm{R} \$$ & 438.34 & $\mathrm{R} \$$ & $1,005.28$ & $\mathrm{R} \$$ & 864.09 \\
\hline 59 & $\mathrm{R} \$ \mathbf{5 7 1 . 1 6}$ & $\mathrm{RS}$ & 434.12 & $\mathrm{RS}$ & $1,005.28$ & $\mathrm{R} \$$ & 429.97 \\
\hline 60 & $\mathrm{R} \$ 575.31$ & $\mathrm{RS}$ & 429.97 & $\mathrm{RS}$ & $1,005.28$ & $\mathrm{RS}$ & 0.00 \\
\hline
\end{tabular}

Fonte: dados da pesquisa (2019) 
Apresentado o recálculo do contrato pelo SEJS, o ato seguinte é verificar os valores pagos a maior pelo mutuário em decorrência da mudança do sistema de amortização. Para tanto, obteve-se a diferença entre a prestação mensal paga no sistema francês de amortização e a prestação mensal do sistema de equivalência a juros simples. Além disso, aproveita-se o ato para realizar a correção monetária da diferença, conforme constou na sentença, pelo IPCA/IBGE. Na data da realização deste artigo, o IPCA mais recente divulgado era o de janeiro/2019. Portanto, a correção monetária foi realizada para tal época. Essa etapa é apresentada na Tabela 4.

Tabela 4 - diferenças devidas em favor do mutuário

\begin{tabular}{|c|c|c|c|c|c|c|c|c|c|c|}
\hline \multirow{2}{*}{$\begin{array}{l}\mathbf{P} \\
1\end{array}$} & \multirow{2}{*}{$\begin{array}{c}\text { Compet. } \\
\text { fev/12 }\end{array}$} & \multicolumn{2}{|c|}{ Prest. Price } & \multicolumn{2}{|c|}{ Prest. SEJS } & \multicolumn{2}{|c|}{ Diferença } & \multirow{2}{*}{$\begin{array}{l}\text { IPCA } \\
1.484 \\
\end{array}$} & \multicolumn{2}{|c|}{ Dif. Corrigida } \\
\hline & & $\mathrm{RS}$ & $1,174.01$ & $\mathrm{RS}$ & $1,005.28$ & $\mathrm{R} \$$ & 168.73 & & $\mathrm{R} \$$ & 250.31 \\
\hline 2 & $\mathrm{mar} / 12$ & $\mathrm{RS}$ & $1,174.01$ & $\mathrm{RS}$ & $1,005.28$ & $\mathrm{R} \$$ & 168.73 & 1.480 & $\mathrm{R} \$$ & 249.79 \\
\hline 3 & $a b r / 12$ & $\mathrm{R} \$$ & $1,174.01$ & $\mathrm{RS}$ & $1,005.28$ & $\mathrm{R} \$$ & 168.73 & 1.471 & $\mathrm{R} \$$ & 248.20 \\
\hline 4 & mai/12 & $\mathrm{R} \$$ & $1,174.01$ & $\mathrm{R} \$$ & $1,005.28$ & $\mathrm{R} \$$ & 168.73 & 1.466 & $\mathrm{R} \$$ & 247.31 \\
\hline 5 & jun/12 & $\mathrm{R} \$$ & $1,174.01$ & $\mathrm{RS}$ & $1,005.28$ & $\mathrm{R} \$$ & 168.73 & 1.465 & $\mathrm{R} \$$ & 247.11 \\
\hline 6 & $\mathrm{jul} / 12$ & $\mathrm{RS}$ & $1,174.01$ & $\mathrm{R} \$$ & $1,005.28$ & $\mathrm{R} \$$ & 168.73 & 1.458 & $\mathrm{R} \$$ & 246.05 \\
\hline 7 & ago/12 & $\mathrm{R} \$$ & $1,174.01$ & $\mathrm{RS}$ & $1,005.28$ & $\mathrm{R} \$$ & 168.73 & 1.452 & $\mathrm{R} \$$ & 245.05 \\
\hline 8 & set/12 & $\mathrm{R} \$$ & $1,174.01$ & $\mathrm{R} \$$ & $1,005.28$ & $\mathrm{R} \$$ & 168.73 & 1.444 & $\mathrm{R} \$$ & 243.66 \\
\hline 9 & out/12 & $\mathrm{R} \$$ & $1,174.01$ & $\mathrm{R} \$$ & $1,005.28$ & $\mathrm{R} \$$ & 168.73 & 1.436 & $\mathrm{R} \$$ & 242.23 \\
\hline 10 & nov/12 & $\mathrm{RS}$ & $1,174.01$ & $\mathrm{R} \$$ & $1,005.28$ & $\mathrm{R} \$$ & 168.73 & 1.427 & $\mathrm{R} \$$ & 240.79 \\
\hline 11 & dez/12 & $\mathrm{R} \$$ & $1,174.01$ & $\mathrm{R} \$$ & $1,005.28$ & $\mathrm{R} \$$ & 168.73 & 1.416 & $\mathrm{R} \$$ & 238.90 \\
\hline 12 & jan/13 & $\mathrm{R} \$$ & $1,174.01$ & $\mathrm{R} \$$ & $1,005.28$ & $\mathrm{R} \$$ & 168.73 & 1.404 & $\mathrm{RS}$ & 236.86 \\
\hline 13 & $\mathrm{fev} / 13$ & $\mathrm{RS}$ & $1,174.01$ & $\mathrm{RS}$ & $1,005.28$ & $\mathrm{R} \$$ & 168.73 & 1.395 & $\mathrm{R} \$$ & 235.45 \\
\hline 14 & $\mathrm{mar} / 13$ & $\mathrm{RS}$ & $1,174.01$ & $\mathrm{RS}$ & $1,005.28$ & $\mathrm{R} \$$ & 168.73 & 1.389 & $\mathrm{RS}$ & 234.35 \\
\hline 15 & $\mathrm{abr} / 13$ & $\mathrm{RS}$ & $1,174.01$ & $\mathrm{RS}$ & $1,005.28$ & $\mathrm{R} \$$ & 168.73 & 1.381 & $\mathrm{RS}$ & 233.07 \\
\hline 16 & $\mathrm{mai} / 13$ & $\mathrm{RS}$ & $1,174.01$ & $\mathrm{RS}$ & $1,005.28$ & $\mathrm{R} \$$ & 168.73 & 1.376 & $\mathrm{R} \$$ & 232.21 \\
\hline 17 & jun/13 & $\mathrm{RS}$ & $1,174.01$ & $\mathrm{RS}$ & $1,005.28$ & $\mathrm{R} \$$ & 168.73 & 1.373 & $\mathrm{RS}$ & 231.61 \\
\hline 18 & jul/13 & $\mathrm{R} \$$ & $1,174.01$ & $\mathrm{RS}$ & $1,005.28$ & $\mathrm{R} \$$ & 168.73 & 1.372 & $\mathrm{RS}$ & 231.54 \\
\hline 19 & ago/13 & $\mathrm{R} \$$ & $1,174.01$ & $\mathrm{RS}$ & $1,005.28$ & $\mathrm{R} \$$ & 168.73 & 1.369 & $\mathrm{RS}$ & 230.98 \\
\hline 20 & set/13 & $\mathrm{R} \$$ & $1,174.01$ & $\mathrm{RS}$ & $1,005.28$ & $\mathrm{R} \$$ & 168.73 & 1.364 & $\mathrm{RS}$ & 230.18 \\
\hline 21 & out/13 & $\mathrm{R} \$$ & $1,174.01$ & $\mathrm{RS}$ & $1,005.28$ & $\mathrm{RS}$ & 168.73 & 1.356 & $\mathrm{RS}$ & 228.87 \\
\hline 22 & nov/13 & $\mathrm{R} \$$ & $1,174.01$ & $\mathrm{R} \$$ & $1,005.28$ & $\mathrm{R} \$$ & 168.73 & 1.349 & $\mathrm{RS}$ & 227.64 \\
\hline 23 & dez/13 & $\mathrm{R} \$$ & $1,174.01$ & $\mathrm{R} \$$ & $1,005.28$ & $\mathrm{R} \$$ & 168.73 & 1.337 & $\mathrm{RS}$ & 225.57 \\
\hline 24 & jan/14 & $\mathrm{RS}$ & $1,174.01$ & $\mathrm{RS}$ & $1,005.28$ & $\mathrm{RS}$ & 168.73 & 1.330 & $\mathrm{RS}$ & 224.33 \\
\hline 25 & fev/14 & $\mathrm{R} \$$ & $1,174.01$ & $\mathrm{R} \$$ & $1,005.28$ & $\mathrm{R} \$$ & 168.73 & 1.320 & $\mathrm{RS}$ & 222.80 \\
\hline 26 & mar/14 & $\mathrm{R} \$$ & $1,174.01$ & $\mathrm{RS}$ & $1,005.28$ & $\mathrm{R} \$$ & 168.73 & 1.308 & $\mathrm{RS}$ & 220.77 \\
\hline 27 & $\mathrm{abr} / 14$ & $\mathrm{R} \$$ & $1,174.01$ & $\mathrm{R} \$$ & $1,005.28$ & $\mathrm{RS}$ & 168.73 & 1.300 & $\mathrm{R} \$$ & 219.30 \\
\hline 28 & mai/14 & $\mathrm{RS}$ & $1,174.01$ & $\mathrm{RS}$ & $1,005.28$ & $\mathrm{RS}$ & 168.73 & 1.294 & $\mathrm{RS}$ & 218.29 \\
\hline 29 & jun/14 & $\mathrm{R} \$$ & $1,174.01$ & $\mathrm{R} \$$ & $1,005.28$ & $\mathrm{R} \$$ & 168.73 & 1.289 & $\mathrm{RS}$ & 217.42 \\
\hline 30 & jul/14 & $\mathrm{RS}$ & $1,174.01$ & $\mathrm{RS}$ & $1,005.28$ & $\mathrm{RS}$ & 168.73 & 1.288 & $\mathrm{R} \$$ & 217.40 \\
\hline 31 & ago/14 & $\mathrm{R} \$$ & $1,174.01$ & $\mathrm{R} \$$ & $1,005.28$ & $\mathrm{RS}$ & 168.73 & 1.285 & $\mathrm{R} \$$ & 216.86 \\
\hline 32 & set/14 & $\mathrm{R} \$$ & $1,174.01$ & $\mathrm{R} \$$ & $1,005.28$ & $\mathrm{R} \$$ & 168.73 & 1.278 & 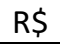 & 215.63 \\
\hline 33 & out/14 & $\mathrm{R} \$$ & $1,174.01$ & $\mathrm{RS}$ & $1,005.28$ & $\mathrm{R} \$$ & 168.73 & 1.273 & $\mathrm{R} \$$ & 214.73 \\
\hline 34 & nov/14 & $\mathrm{RS}$ & $1,174.01$ & $\mathrm{RS}$ & $1,005.28$ & $\mathrm{RS}$ & 168.73 & 1.266 & $\mathrm{RS}$ & 213.64 \\
\hline 35 & dez/14 & $\mathrm{R} \$$ & $1,174.01$ & $\mathrm{R} \$$ & $1,005.28$ & $\mathrm{R} \$$ & 168.73 & 1.256 & $\mathrm{R} \$$ & 211.98 \\
\hline 36 & jan/15 & $\mathrm{R} \$$ & $1,174.01$ & $\mathrm{R} \$$ & $1,005.28$ & $\mathrm{R} \$$ & 168.73 & 1.241 & $\mathrm{R} \$$ & 209.39 \\
\hline 37 & fev/15 & $\mathrm{R} \$$ & $1,174.01$ & $\mathrm{R} \$$ & $1,005.28$ & $\mathrm{R} \$$ & 168.73 & 1.226 & $\mathrm{R} \$$ & 206.86 \\
\hline 38 & mar/15 & $\mathrm{R} \$$ & $1,174.01$ & $\mathrm{R} \$$ & $1,005.28$ & $\mathrm{R} \$$ & 168.73 & 1.210 & $\mathrm{R} \$$ & 204.17 \\
\hline 39 & $\mathrm{abr} / 15$ & $\mathrm{R} \$$ & $1,174.01$ & $\mathrm{R} \$$ & $1,005.28$ & $\mathrm{R} \$$ & 168.73 & 1.202 & $\mathrm{R} \$$ & 202.73 \\
\hline 40 & mai/15 & $\mathrm{R} \$$ & $1,174.01$ & $\mathrm{R} \$$ & $1,005.28$ & $\mathrm{R} \$$ & 168.73 & 1.193 & $\mathrm{R} \$$ & 201.24 \\
\hline 41 & jun/15 & $\mathrm{R} \$$ & $1,174.01$ & $\mathrm{R} \$$ & $1,005.28$ & $\mathrm{R} \$$ & 168.73 & 1.183 & $\mathrm{R} \$$ & 199.66 \\
\hline 42 & jul/15 & $\mathrm{R} \$$ & $1,174.01$ & $\mathrm{R} \$$ & $1,005.28$ & $\mathrm{R} \$$ & 168.73 & 1.176 & $\mathrm{R} \$$ & 198.43 \\
\hline 43 & ago/15 & $\mathrm{R} \$$ & $1,174.01$ & $\mathrm{RS}$ & $1,005.28$ & $\mathrm{R} \$$ & 168.73 & 1.173 & $\mathrm{R} \$$ & 198.00 \\
\hline 44 & set/15 & $\mathrm{R} \$$ & $1,174.01$ & $\mathrm{R} \$$ & $1,005.28$ & $\mathrm{RS}$ & 168.73 & 1.167 & $\mathrm{RS}$ & 196.93 \\
\hline
\end{tabular}




\begin{tabular}{|c|c|c|c|c|c|c|c|c|c|c|}
\hline 45 & out/15 & $\mathrm{RS}$ & $1,174.01$ & $\mathrm{R} \$$ & $1,005.28$ & $\mathrm{R} \$$ & 168.73 & 1.158 & $\mathrm{R} \$$ & 195.33 \\
\hline 46 & nov/15 & $\mathrm{R} \$$ & $1,174.01$ & $\mathrm{R} \$$ & $1,005.28$ & $\mathrm{RS}$ & 168.73 & 1.146 & $\mathrm{R} \$$ & 193.38 \\
\hline 47 & dez/15 & $\mathrm{RS}$ & $1,174.01$ & $\mathrm{RS}$ & $1,005.28$ & $\mathrm{RS}$ & 168.73 & 1.135 & $\mathrm{RS}$ & 191.54 \\
\hline 48 & jan/16 & $\mathrm{RS}$ & $1,174.01$ & $\mathrm{RS}$ & $1,005.28$ & $\mathrm{R} \$$ & 168.73 & 1.121 & $\mathrm{R} \$$ & 189.14 \\
\hline 49 & fev/16 & $\mathrm{RS}$ & $1,174.01$ & $\mathrm{RS}$ & $1,005.28$ & $\mathrm{R} \$$ & 168.73 & 1.111 & $\mathrm{RS}$ & 187.45 \\
\hline 50 & $\mathrm{mar} / 16$ & $\mathrm{R} \$$ & $1,174.01$ & $\mathrm{RS}$ & $1,005.28$ & $\mathrm{RS}$ & 168.73 & 1.106 & $\mathrm{R} \$$ & 186.65 \\
\hline 51 & $\mathrm{abr} / 16$ & $\mathrm{R} \$$ & $1,174.01$ & $\mathrm{R} \$$ & $1,005.28$ & $\mathrm{R} \$$ & 168.73 & 1.099 & $\mathrm{R} \$$ & 185.52 \\
\hline 52 & mai/16 & $\mathrm{RS}$ & $1,174.01$ & $\mathrm{RS}$ & $1,005.28$ & $\mathrm{R} \$$ & 168.73 & 1.091 & $\mathrm{R} \$$ & 184.08 \\
\hline 53 & jun/16 & $\mathrm{RS}$ & $1,174.01$ & $\mathrm{RS}$ & $1,005.28$ & $\mathrm{RS}$ & 168.73 & 1.087 & $\mathrm{RS}$ & 183.44 \\
\hline 54 & jul/16 & $\mathrm{RS}$ & $1,174.01$ & $\mathrm{RS}$ & $1,005.28$ & $\mathrm{RS}$ & 168.73 & 1.082 & $\mathrm{RS}$ & 182.49 \\
\hline 55 & ago/16 & $\mathrm{R} \$$ & $1,174.01$ & $\mathrm{R} \$$ & $1,005.28$ & $\mathrm{R} \$$ & 168.73 & 1.077 & $\mathrm{R} \$$ & 181.69 \\
\hline 56 & set/16 & $\mathrm{RS}$ & $1,174.01$ & $\mathrm{R} \$$ & $1,005.28$ & $\mathrm{RS}$ & 168.73 & 1.076 & $\mathrm{RS}$ & 181.55 \\
\hline 57 & out/16 & $\mathrm{RS}$ & $1,174.01$ & $\mathrm{RS}$ & $1,005.28$ & $\mathrm{RS}$ & 168.73 & 1.073 & $\mathrm{RS}$ & 181.08 \\
\hline 58 & nov/16 & $\mathrm{R} \$$ & $1,174.01$ & $\mathrm{R} \$$ & $1,005.28$ & $\mathrm{R} \$$ & 168.73 & 1.071 & $\mathrm{R} \$$ & 180.75 \\
\hline 59 & $\mathrm{dez} / 16$ & $\mathrm{R} \$$ & $1,174.01$ & $\mathrm{R} \$$ & $1,005.28$ & $\mathrm{R} \$$ & 168.73 & 1.068 & $\mathrm{R} \$$ & 180.21 \\
\hline \multirow[t]{2}{*}{60} & jan/17 & $\mathrm{R} \$$ & $1,174.01$ & $\mathrm{R} \$$ & $1,005.28$ & $\mathrm{RS}$ & 168.73 & 1.064 & $\mathrm{R} \$$ & 179.53 \\
\hline & SOMA & $\mathbf{R} \$$ & $70,440.60$ & $\mathbf{R} \$$ & $60,316.80$ & $\mathbf{R} \$$ & $10,123.80$ & & $\mathbf{R} \$$ & $12,872.11$ \\
\hline
\end{tabular}

Fonte: dados da pesquisa (2019)

Conforme se verifica na Tabela 4, caso o mutuário tivesse efetuado os pagamentos desde o início da amortização com base no SEJS, teria deixado de sofrer perdas em seus fluxos de caixa da ordem de $\mathrm{R} \$ 10.123,80$ (em valores nominais), ou seja, a diminuição do seu patrimônio em decorrência do pagamento das prestações mensais seria bem menor do que efetivamente foi.

O valor total a ser restituído ao mutuário, por conta do afastamento do sistema francês de amortização e recálculo do contrato pelo sistema de equivalência a juros simples, devidamente corrigido pelo IPCA, é de R\$12.872,11, conforme evidenciado no quadro 5.

No entanto, resta ainda incluir neste valor os juros de mora definidos em sentença, de $1 \%$ a.m., com capitalização simples. Os juros de mora são sempre contados a partir da citação do réu no processo, fato que se deu em 16/01/2017. Portanto, empregando o critério prórata-die para cálculo dos juros, entre a data da citação e a data de elaboração deste artigo (27/01/2019) passaram-se 741 dias. Dividindo-se a taxa de juros determinada em sentença (1\% a.m.) por 30 dias (mês comercial), tem-se que a taxa de juros simples diária é de $0,0333 \%$, que multiplicada por 741 dias retorna a taxa total de juros do período de $24,70 \%$.

Embora adotado o formato de cálculo dos juros com base no critério acima descrito, seu emprego não é unânime, tampouco isento de críticas, visto que retorna juros superiores a $12 \%$ a.a., fato que, muitas vezes, gera impugnações dos cálculos periciais pelos advogados. Neste caso, considerando que consta expressamente da sentença sua adoção, manteve-se sua aplicação, porém, eventualmente em outro processo, ter-se-ia que realizar ajustes no cálculo dos juros, o que de toda sorte, geraria uma pequena diferença no percentual de juros a ser aplicado.

Desta forma, incluindo-se o percentual de juros $(24,70 \%)$ sobre o valor corrigido devido ao mutuário ( $R \$ 12.872,11$ ), chega-se ao valor final devido de $\mathrm{R} \$ 16.051,52$ (dezesseis mil, cinquenta e um reais e cinquenta e dois centavos), que corresponde ao valor total a ser pago pela XX Financeira S/A ao sr. J.S.F. em decorrência do processo ora analisado.

Graficamente, tem-se o seguinte panorama em relação aos valores pagos pelo mutuário nas prestações pelo sistema francês, nos valores que deveriam ter sido pagos pelo sistema de equivalência a juros simples, e os valores das diferenças corrigidas: 
Gráfico 1: comparativo entre valores dos sistemas de amortização

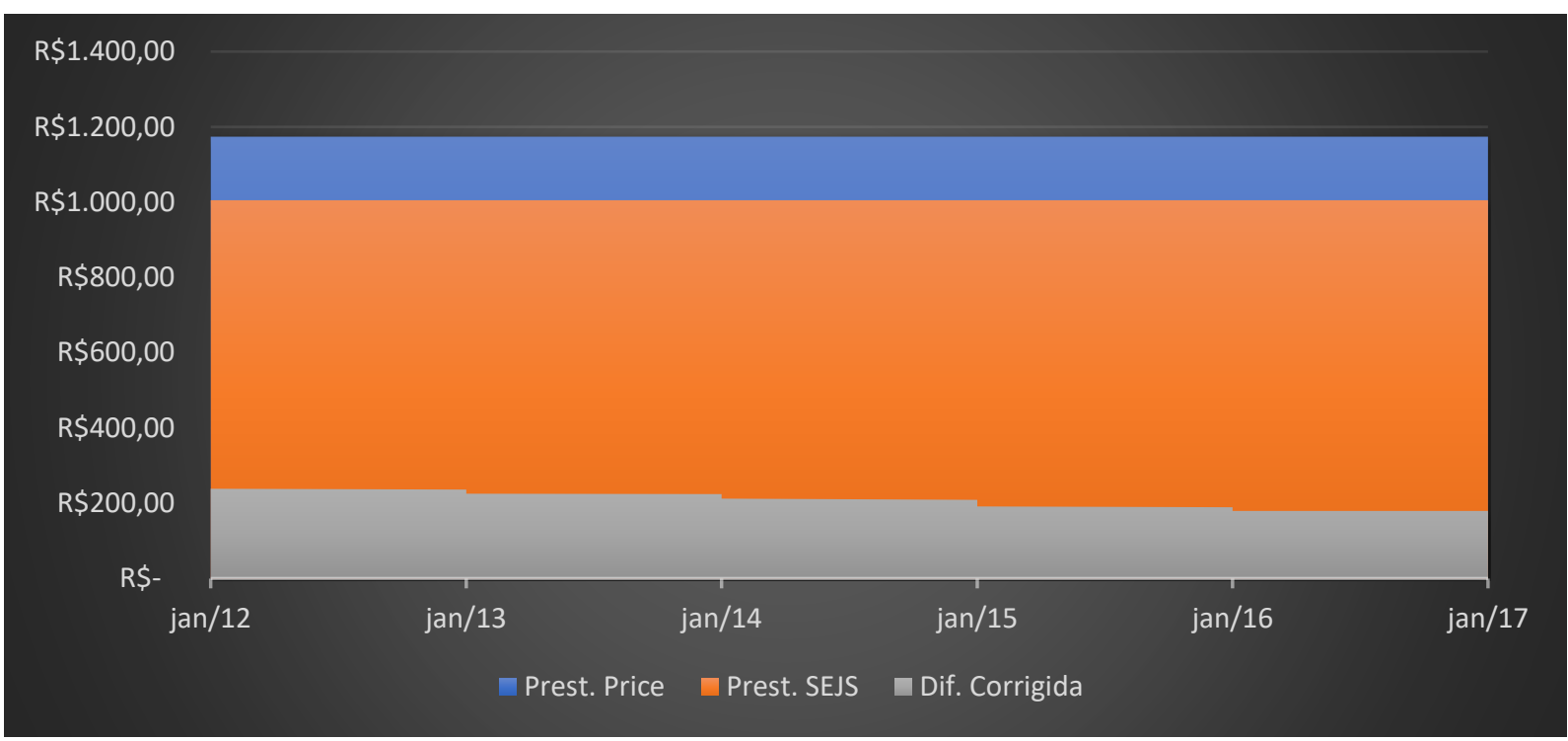

Fonte: dados da pesquisa (2019)

Por fim, salienta-se que não foram incluídos no cálculo o valor dos honorários advocatícios arbitrados pelo Juízo $(\mathrm{R} \$ 5.000,00)$ pois o interesse da pesquisa está em apontar o valor devido ao mutuário. Porém, em uma situação real envolvendo um cálculo desta natureza, bastaria adotar os procedimentos indicados na sentença para tal valor e promover sua correção monetária de acordo com a data da sentença, bem como o acréscimo de juros se previstos na decisão.

De posse de todos esses cálculos e análises realizados, o perito deve incluí-los no bojo de um laudo pericial, observando a estrutura de laudo preconizada pelo Conselho Federal de Contabilidade e os elementos do laudo pericial previstos no Código de Processo Civil, conforme discutido na seção de revisão de literatura.

Apresentados e discutidos os resultados da pesquisa conforme descritos nesta seção 4, em seguida apresenta-se as considerações finais do estudo.

\section{CONSIDERAÇÕES FINAIS}

Embora a perícia contábil constitua uma especialidade das mais importantes da ciência contábil, trabalhos empíricos envolvendo temas do dia-a-dia profissional são raros na academia. São comuns pesquisas envolvendo questões como a qualidade do laudo pericial na ótica do magistrado, ou percepção dos alunos a respeito da disciplina de perícia contábil no período da graduação, porém, estudos aplicados, como ora desenvolvido, são raros.

Evidentemente que todas as pesquisas científicas são relevantes, mas estudos que aproximam a academia de temas do cotidiano profissional possuem, certamente, grande importância, em especial pelo potencial de que tais conhecimentos sejam disseminados e empregados entre os profissionais da área. Nesse sentido, acredita-se que o artigo atende essa finalidade.

O estudo teve como objetivo analisar a economia proporcionada ao mutuário que tem seu contrato de financiamento de veículo amortizado pelo sistema de equivalência a juros simples em detrimento da amortização pelo sistema francês de amortização (tabela Price), mensurando a diferença dos fluxos de caixa gerada pela substituição do sistema de amortização e seus efeitos no patrimônio pessoal do mutuário. 
Para atingir o objetivo proposto, analisou-se um contrato real de financiamento de veículos, sub judice, originalmente amortizado pelo sistema francês de amortização, em que se realizou o recálculo do contrato à juros simples, com base nas disposições previstas na sentença.

Após a realização de todos os procedimentos destacados ao longo do estudo, o objetivo foi alcançado, uma vez que, recalculando-se o contrato com base no SEJS, verificouse uma economia total para o mutuário da ordem de $\mathrm{R} \$ 12.872,11$ (doze mil, oitocentos e setenta e dois reais e onze centavos), devidamente corrigida.

Por fim, respondendo ao problema da pesquisa, qual seja, Qual a economia proporcionada ao mutuário pela amortização de um contrato de financiamento pelo SEJS em detrimento da tabela Price?, verificou-se que caso o contrato de financiamento tivesse sido amortizado desde o início pelo SEJS, o cliente teria obtido uma economia de $\mathrm{R} \$ 12.872,11$. Incluindo-se os juros devidos ao mutuário em razão do recálculo do financiamento, o reflexo total nos seus fluxos de caixa e, portanto, seu patrimônio pessoal, seriam da ordem de $\mathrm{R} \$$ 16.051,52 (dezesseis mil, cinquenta e um reais e cinquenta e dois centavos), que corresponde ao valor que a XX Financeira S/A deverá pagar ao mutuário em decorrência do processo.

Salientando, apenas, que esse valor pode aumentar caso a Financeira não efetue o pagamento no prazo indicado pelo juízo em decorrência da realização de nova correção monetária e inclusão de novos juros ao valor principal.

Com o recálculo do sistema de amortização do contrato, verificou-se que o sistema de equivalência a juros simples (SEJS) é mais econômico ao mutuário, porém, seu emprego pelos Tribunais tende a causar alguma insegurança jurídica às instituições financeiras, visto que a qualquer momento podem sofrer interferência nas suas operações pela ação do Judiciário, como no caso ora analisado, em que foi afastada a aplicação do sistema de amortização original contratado, determinando todo o recálculo do contrato. Entretanto, observando a questão sob o prisma do consumidor, muitas instituições financeiras operam ao arrepio da lei, praticando taxas e condutas abusivas contra os clientes (como a questão da taxa de juros praticada no caso analisado, diferente da informada em contrato pela Financeira), que requerem o socorro do Judiciário para equalizar a questão.

Esse fato, bem como os demais discutidos ao longo da revisão bibliográfica evidenciam que o assunto parece longe de uma solução que atenda tanto aos interesses das instituições financeiras quanto dos clientes. Com isso, a judicialização dessas controvérsias tende a continuar. Com mais ações judiciais sobre o tema, o trabalho do perito contador em casos análogos tende a ser cada vez mais demandado, visto que por se tratar de questão técnica, é necessária a realização de perícia com objetivo de apresentar a liquidação das sentenças relativas a estes processos.

Do ponto de vista da prática profissional, a realização desse tipo de perícia é recorrente para os contadores, em especial pelo volume de ações desta natureza em trâmite em todo o país. Para que o juiz possa dar prosseguimento ao processo, apontando o valor total devido ao mutuário, se faz necessária a realização da perícia e a apresentação dos valores em laudo pericial, seja ele produzido pelas partes, seja produzido por perito nomeado pelo Juiz.

Com o emprego dos fundamentos matemáticos discutidos ao longo desta pesquisa, e seguindo-se um protocolo similar ao deste estudo, é perfeitamente possível ao profissional da perícia oferecer uma solução tecnicamente adequada ao juízo em demandas similares, embora, como já frisado, não exista apenas o sistema de equivalência a juros simples como técnica para recálculo de contratos financeiros, cabendo ao profissional escolher a metodologia mais adequada, justificar seu emprego e aplicá-la ao caso concreto. 
Evidentemente que questionamentos por parte dos assistentes técnicos podem surgir face ao laudo do perito, porém, isso faz parte do rito processual, em que os assistentes técnicos buscam, defender os interesses dos seus contratantes, o que resulta, muitas vezes, em impugnações ao trabalho do perito, visando desconstituir o laudo em favor de tese mais favorável ao seu cliente.

Por fim, como sugestão para futuras pesquisas, recomenda-se a realização de estudos similares envolvendo outras temáticas do dia-a-dia do profissional da perícia, como em processos trabalhistas, previdenciários ou mesmo cíveis de outras naturezas. Um estudo comparativo sobre a jurisprudência dominante em diferentes tribunais do país também poderia ser realizado para analisar qual é o entendimento majoritário dos tribunais nacionais a respeito das ações revisionais envolvendo o sistema francês de amortização.

\section{REFERÊNCIAS}

ASSAF NETO, Alexandre. Matemática financeira e suas aplicações. São Paulo: Atlas, 2001.

BONFÁ, Maria Olívia Ramos. Limitação dos Juros Bancários Após a Emenda Constitucional n 40 De 2003. Revista Vianna Sapiens, Juiz de Fora, v. 3, n. 1, p. 26-26, jan/jun. 2012.

BEUREN, Ilse Maria. Como elaborar trabalhos monográficos em contabilidade: teoria e prática. São Paulo: Atlas, 2003.

BRASIL. Decreto 22.626, de 7 de abril de 1933. Dispõe sobre os juros nos contratos e da outras providencias. Diário Oficial da União, Brasília-DF, 8 de abril de 1933. Disponível em: < http://www.planalto.gov.br/ccivil_03/decreto/D22626.htm>. Acesso em: 27 de janeiro 2019.

BRASIL. Decreto-Lei n. 9.295, de 27 de maio de 1946. Cria o Conselho Federal de Contabilidade, define as atribuições do Contador e do Guarda-livros, e dá outras providências. Diário Oficial da União, Brasília-DF, 28 de maio de 1946. Disponível em: < http://www.planalto.gov.br/ccivil_03/decreto-lei/Del9295.htm>. Acesso em: 27 de janeiro 2019.

BRASIL. Medida Provisória no 2.170-36, de 23 de agosto de 2001. Dispõe sobre a administração dos recursos de caixa do Tesouro Nacional, consolida e atualiza a legislação pertinente ao assunto e dá outras providências. Diário Oficial da União, Brasília-DF, 24 de agosto de 2001. Disponível em: < http://www.planalto.gov.br/ccivil_03/MPV/2170-36.htm>. Acesso em: 27 de janeiro 2019.

BRASIL. Lei n. 13.105, de 16 de março de 2015. Código de Processo Civil. Diário Oficial da União, Brasília-DF, 17 de março de 2015. Disponível em: < http://www.planalto.gov.br/ccivil_03/_Ato2015-2018/2015/Lei/L13105.htm>. Acesso em: 27 de janeiro 2019.

CFC. Resolução CFC no 2015/NBCTP01. Dá nova redação à NBC TP 01 - Perícia Contábil. Diário Oficial da União, Brasília-DF, 19 de março de 2015. Disponível em: < http://www1.cfc.org.br/sisweb/sre/detalhes_sre.aspx?Codigo=2015/NBCTP01>. Acesso em: 7 de julho 2019. 
CFC. Resolução CFC no 2015/NBCPP01. Dá nova redação à NBC PP 01 - Perito Contábil. Diário Oficial da União, Brasília-DF, 19 de março de 2015. Disponível em:

http://www1.cfc.org.br/sisweb/sre/detalhes_sre.aspx?Codigo=2015/NBCPP01>. Acesso em: 7 de julho 2019.

CFC. Resolução CFC no 2016/NBCPP02. Aprova a NBC PP 02, que dispõe sobre o exame de Qualificação Técnica para o Perito Contábil. Diário Oficial da União, Brasília-DF, 28 de outubro de 2016. Disponível em:

http://www2.cfc.org.br/sisweb/sre/detalhes_sre.aspx?Codigo=2016/NBCPP02\&arquivo=NB CPP02.doc>. Acesso em: 7 de julho 2019.

DE-LOSSO, Rodrigo; RANGEL, Armênio; GIOVANNETTI, Bruno Cara. Sistema de Amortização por Múltiplos Contratos: a falácia do sistema francês/Amortization System by Multiple Contracts: the French system fallacy. Economic Analysis of Law Review, Brasília, v. 4, n. 1, p. 160-181, jan/jun. 2013.

DOMINGUES, Gabriel Demetrio. Capitalização dos juros por instituições financeiras: uma análise do panorama legislativo e jurisprudencial. Revista do BNDES, Rio de Janeiro, n. 35, p. 169-184, 2011.

DE FARO, Clovis. Uma nota sobre amortização de dívidas: juros compostos e anatocismo. Revista Brasileira de Economia, Rio de Janeiro, v. 67, n. 3, p. 283-295, jul/set. 2013. Doi: http://dx.doi.org/10.1590/S0034-71402013000300002

FIGUEIREDO, Sandra; MOURA, Heber. A utilização dos Métodos Quantitativos pela Contabilidade. Revista Brasileira de Contabilidade, Brasília, v. 1, n. 2, p. 51-61, mar/abr. 2001.

GIL, Antonio Carlos. Pesquisa social. São Paulo: Atlas, 1999.

IGUAL, David. Conocer los productos y servicios bancarios: Productos de tesorería, de inversión, de financiación, leasing, factoring, renting, tarjetas. Profit editorial, 2008.

JANSSEN, Jacques; MANCA, Raimondo; VOLPE, Ernesto. Mathematical finance: deterministic and stochastic models. John Wiley \& Sons, 2013.

MAGALHÃES, Antonio de Deus Farias. Perícia contábil: uma abordagem teórica, ética, legal, processual e operacional: casos praticados. São Paulo: Atlas, 2017.

NEVES JÚNIOR, Idalberto José; BRITO, Cristiane Pereira. A competência profissional de peritos-contadores no desenvolvimento da prova pericial contábil no âmbito do Ministério Público do Distrito Federal e Territórios. Revista Brasileira de Contabilidade, Brasília, n. 165, p. 52-63, mai/jun. 2007.

NEVES JUNIOR, Idalberto José; CERQUEIRA, João Guilherme Moreira; GOTTARDO, Michele dos Santos Povoas. Perícia Contábil Judicial: A Relevância e a Qualidade do Laudo Pericial 
Contábil na Visão dos Magistrados do Estado do Rio de Janeiro. In: Anais do XXXVII Encontro da ANPAD, 2013.

RICHARDSON, Roberto Jarry. Pesquisa Social: métodos e técnicas (pp. 189-206). 1999.

SANDRINI, Jackson Ciro. Sistemas de amortização de empréstimos e a capitalização de juros: análise dos impactos financeiros e patrimoniais (Dissertação de Mestrado, Universidade Federal do Paraná), 2007.

STF. Súmula no 121. Sessão Plenária de 13/12/1963. Disponível em: < http://www.stf.jus.br/portal/jurisprudencia/listarJurisprudencia.asp?s1=121.NUME.\%20NA O\%20S.FLSV.\&base=baseSumulas >. Acesso em 27 de janeiro de 2019.

STF. Súmula no 596. Sessão Plenária de 15/12/1976. Disponível em: < http://www.stf.jus.br/portal/jurisprudencia/listarJurisprudencia.asp?s1=596.NUME.\%20NA O\%20S.FLSV.\&base=baseSumulas $>$. Acesso em 27 de janeiro de 2019.

TJPR. Apelação Cível no 6789997. Disponível em: <https://tjpr.jusbrasil.com.br/jurisprudencia/19490930/apelacao-civel-ac-6789997-pr-06789997/inteiro-teor-104351840>. Acesso em 27 de janeiro de 2019.

TJSP. Agravo de Instrumento no 2167146-08.2018.8.26.0000. Disponível em: <https://www.jusbrasil.com.br/diarios/documentos/658994966/andamento-do-processo-n2167146-0820188260000-agravo-de-instrumento-14-12-2018-do-tjsp?ref=topic_feed>. Acesso em 27 de janeiro de 2019.

VERAS, Lílian Ladeira. Matemática Financeira: uso de calculadoras financeiras, aplicações ao mercado financeiro. 4. ed. - São Paulo: Atlas, 2001.

VERGARA, Sylvia. Projetos e relatórios de pesquisa em administração. 3.ed. Rio de Janeiro: Atlas, 2000.

ZANNA, Remo Dalla. Prática de perícia contábil. 4. ed. São Paulo: IOB, 2013.

ZANNA, Remo Dalla. Perícia Contábil em Matéria Financeira. 4. ed. São Paulo: IOB, 2015. 